\title{
Larval morphology of spring-living water mites (Hydrachnidia, Acari) from the Alps
}

\author{
P. Martin \\ Christian-Albrechts-Universität zu Kiel, Zoologisches Institut, Abteilung Limnologie, Olshausenstr. 40, D-24098 Kiel, Germany.
} Email: pmartin@zoologie.uni-kiel.de

\begin{abstract}
The larval morphology of 20 water mite species from Alpine springs is described, with that of Protzia distincta, Tartarothyas romanica, Sperchon mutilus, S. resupinus, S. violaceus, Bandakia concreta, Lebertia cuneifera, L. lativentris, L. sefvei, Atractides adnatus, A. panniculatus, A. macrolaminatus and A. walteri being presented for the first time. For the other 7 species (Panisus michaeli, Panisopsis curvifrons, Thyas palustris, Partnunia steinmanni, Sperchon thienemanni, Lebertia zschokkei and Hygrobates norvegicus), old descriptions exist but, in most cases are not accurate enough to be usable in taxonomy. These species have therefore been re-described. Some general observations on larval morphology and taxonomy are discussed. A short survey of the larval descriptions of West-Palaearctic water mites in general and of spring-living taxa in particular is given, together with a perspective for future research into larval morphology in this geographical area.
\end{abstract}

Keywords : water mites, Hydrachnidia, larval morphology, springs, Alps, West-Palaearctis.

\section{Introduction}

The general life cycle of water mites is marked by three free-living stages (Böttger 1977). The nymph and the adult are predatory, whereas the larva is an obligatory parasite of various insects.

Because of their conspicuousness and their often reddish colour when attached to various hosts, water mite larvae were early recognized in biology and have often been described (e.g. Krendowskij 1878, Piersig 1896-99, Soar 1901). However, Prasad \& Cook (1972) were the first to provide larval descriptions at a level that enabled species determination. Previous authors who attempted to compile the characters of the larvae in different taxonomic rankings (Viets 1936, Sparing 1959) failed because of the limited number of sound larval descriptions.

In North America, larval taxonomy has been investigated much more extensively, mainly by I.M. Smith who has described many species and made many diagnoses at the superfamily, family and genus level (e.g. Smith 1976, 1982). For the Palaearctis, the most comprehensive work on this subject is the Russian paper of Wainstein (1980), plus only some detailed descriptions of single species (e.g. Tuzovskij 1981, Martin 2000, Gerecke \& Tuzovskij 2001). Nevertheless, even in the- se relatively well-investigated areas, we are far removed from being able to determine water mite larvae at a species level, e.g. from an infested host. There are only some negligible exceptions for some monotypical species from restricted areas (e.g. Limnochares aquati$c a$ in the West-Palaearctis).

Larval and host-parasite associations have been documented for a few spring- and brook-dwelling water mite species, but mainly from North America (Smith \& Oliver 1986, Smith 1991). For spring-living water mites in Central European springs, some old but sound studies are available (e.g. Walter 1922a, b, Viets 1923a, 1925), although the larval descriptions in these studies are mostly incidental and accurate descriptions that can be used taxonomically only exist for a few species. For one crenobiontic species, Lebertia stigmatifera, which was assumed to be a species without a parasitic larva (Lundblad 1924), recent studies have established that, in some populations, a host-associated larval life is necessary (Martin 2000). Thus, it is possible that loss of parasitism is, at least sometimes, a facultative phenomenon that can be reversed. In springs, water mites show a strong relationship to their biotope but this is not well understood. The host specificity of the water mites is possibly the key factor that causes the strong habitat association of mites (Gerecke \& Di 
Sabatino 1996). The first necessary step in elucidating these host-parasite associations is the accurate description of the larval morphology.

The present study was carried out in springs of the Alpine National Park of Berchtesgaden (south-east Germany) where the long-term changes of fauna and abiotic factors are being monitored (see Gerecke et al. 2002). In the faunistic composition of these springs, the water mites represent the group of invertebrates with the most crenobiontic species (Gerecke et al. 1998). The following descriptions of spring-living water mite larvae not only serve to provide better knowledge of larval morphology in general but also aim at answering the question of whether the crenobiontic species are specifically dependent on spring-bound hosts.

\section{Study area and methods}

The larval descriptions in the present study concern species found in two spring complexes of the Alpine National Park of Berchtesgaden. The springs in these complexes were numbered consecutively from the highest point of the complex. The spring complexes consist of different rheocrenes and helocrenes and are located between 1150-1250m a.s.l. A detailed description of the collecting sites will be published elsewhere and is available from the administration of the National Park. Of the more than 40 water mite species found here (Gerecke \& Martin, unpublished data), approximately half could be reared by breeding the eggs laid by determinable females. These mothers mostly derived from the springs themselves but also exceptionally from other sites mentioned in the descriptions below. As a rule, the females were sampled in the field and transported alive to the laboratory. Rearing took place in a climatic chamber at temperatures of about $7^{\circ} \mathrm{C}$. Since most of the descriptions are based on freshly hatched animals, most descriptions represent unengorged larvae. Larvae were embedded in Hoyer's medium or, exceptionally, in glycerine jelly.

The descriptions are based on the general larval morphology of water mites as given in Prasad \& Cook (1972), Martin (1998) or Gerecke \& Tuzovskij (2001). The abbreviation NPB stands for the National Park of Berchtesgaden; other abbreviations used in the descriptions are as follows:

$\begin{array}{ll}\text { CXI-CXIII } & \text { coxal plate I-III } \\ \text { Mp1-Mp2 } & \text { mediopropodosomal setae 1-2 } \\ \text { Lp1-Lp2 } & \text { lateropropodosomal setae 1-2 } \\ \mathrm{Hu} & \text { humeral seta } \\ \text { Lh1-Lh3 } & \text { laterohysterosomal setae 1-3 }\end{array}$

$\begin{array}{ll}\text { Mh1-Mh4 } & \begin{array}{l}\text { mediohysterosomal setae 1-4 } \\ \text { Dp }\end{array} \\ \text { Hy1-2 } & \begin{array}{l}\text { hypostomal setae 1-2 } \\ \text { C1-C4 }\end{array} \\ \text { coxal setae 1-4 } \\ \text { mmcp } & \text { medial margin of coxal plate } \\ \text { Pmcp } & \text { posterior margin of coxal plate } \\ \text { E1-E2 } & \text { excretory pore plate setae 1-2 } \\ \text { V1-V4 } & \text { ventral setae 1-4 } \\ \text { PI-PV } & \text { palpal segment I-V } \\ \text { IL1-IL6 } & \begin{array}{l}\text { 1st. segment of the Ist. leg - 6th. } \\ \text { segment of the Ist. leg }\end{array} \\ \text { IIL1-IIL6 } & \begin{array}{l}\text { 1st. segment of the IInd. leg - 6th. } \\ \text { segment of the IInd. leg }\end{array} \\ \text { IIIL1-IIIL6 } & \begin{array}{l}\text { 1st. segment of the IIIrd. leg - 6th. } \\ \text { segment of the IIIrd. leg }\end{array} \\ \text { Exp } & \text { excretory pore } \\ \text { Expp } & \text { excretory pore plate } \\ \text { se } & \text { seta } \\ \text { so } & \text { solenidion } \\ \text { eu } & \text { eupathidium }\end{array}$

Illustrations were made by using a Zeiss microscope with a drawing mirror. Unless otherwise indicated, all measured distances (in $\mu \mathrm{m}$ ) are given according to Prasad \& Cook (1972) and will be further reported (Martin, unpubl. data). Total leg length refers to the sum of all the leg segments. Measurements of several larvae of the same species are given with the range (minimum and maximum) followed by the mean (in brackets).

"Material examined" refers to the number and the detailed origin of larvae on which the description is based. Sometimes, the number of examined larvae varied for different characters. Under these circumstances, the number of measured specimens (in brackets) precedes the character and refers to all following characters until another number of the measured specimen is given.

A differential analysis and a key enabling the presented larvae (and other previously described taxa) to be distinguished will be published elsewhere (Martin, unpubl. data). Therefore, in the present descriptions, only those characters that relate to differences between the described larvae are given.

\section{Descriptions}

Unless otherwise stated, a family diagnosis introduces the sections that have been compiled based on Prasad \& Cook (1972), Wainstein (1980), Smith (1982), and my own observations. 
The eupathidia of the water mite legs are difficult to recognize by light microscopy with the exception of the larvae of the Hydryphantidae. Therefore, they are only reported in the following descriptions if they were clearly visible.

\section{Family: Hydryphantidae Piersig, 1896}

Diagnosis: Dorsal plate small, covering less than one third of the length of the idiosoma and bearing 2 or 4 pairs of propodosomal setae; lateral eyes on each side lying separately in the soft integument; humeral, hysterosomal and ventral setae often borne on platelets of different extent (which are sometimes barely visible); coxal plates I to III small, separate and with 3 or 4 pairs of coxal setae; cheliceral bases separated from each other; palpal claw single or bifurcate; legs I to III sixsegmented and each leg with three claws of which the lateral claws are extremely thin; distal segments of legs I to III very narrow distally.

For the Thyadinae (Panisus, Panisopsis and Protzia), the following chaetotaxy was reported by Wainstein (1980): IL1 1se, IL2 2se, IL3 5se, IL4 $4 \mathrm{se}+1 \mathrm{so}+1 \mathrm{eu}$, IL5 $10 \mathrm{se}+2 \mathrm{so}+1 \mathrm{eu}$, IL6 20se+1so+1eu; IIL1 1se, IIL2 2se, IIL3 5se, IIL4 4se+1so+1eu, IIL5 10se+2so + 20se+1so+1eu; IIIL1 1se, IIIL2 1se, IIIL3 5 se, IIIL4 4 se +1 so, IIII5 10se+1so, IIIL6 20se. The descriptions below showed that this setation, which was based on data for only a single species, is no longer valid. The family obviously presents not only a highly variable adult (and nymphal) morphology but also a broad range of larval morphology. Therefore, a larval diagnosis of the subfamilies should be postponed to a later date. All the Hydryphantidae presented here are characterized by CXI with two setae, and CXII and CXIII with one seta on each. The length of the legs seems to decrease from IL to IIIL and IIL, although there are some older reports giving other data, but these mostly refer to larvae that have not yet hatched. In past descriptions of many hydryphantoid larvae, the Dp was overlooked (e.g. Walter 1915, Lundblad 1927, Biesiadka \& Cichoka 1984, Ullrich 1976, Martin 2000) but it remains open whether the Dp is actually a family-specific character.

Subfamily: Thyadinae (Viets, 1926)

Panisus michaeli Koenike, 1896

Material examined: 14 larvae reared from females from spring no. 696 (NPB): measurements were taken from 5 specimens.

Morphology: Habitus of the idiosoma slightly ovate (Fig. 1a, b), all idiosomal setae smooth and not pinnate. Platelets on which the idiosomal setae are borne re- latively large but sometimes only barely visible, length of idiosoma 200-213 (207), width 155-188 (173).

Dorsal idiosoma (Fig. 1a): Dp a little wider than long, anteriorly smaller than posteriorly, laterally distinctly constricted, length of Dp 60-65 (62), width 6786 (78), medially of Lp2 insertion of two distinct dots. Anterior eye capsule lateral of the constriction of the Dp, length of the anterior eye capsule 17-19 (18), Mp2-Amdp 42-55 (50), Mp1-Mp1 25-31 (28), Mp2Mp2 33-37 (35), Lp1-Lp1 52-59 (56), Lp2-Lp2 52-54 (52), Mp1-Lp1 17-19 (18), Mp2-Lp2 15-16 (16), Mp1Mp2 35-40 (38), Lp1-Lp2 35-39 (37), Mp1 110-120 (114), Mp2 93-96 (95), Lp1 69-81 (76), Lp2 59-67 (63), Hu 80-83 (82), Mh1 57-61 (59), Mh2 62-70 (67), Mh3 65-73 (68), Mh4 62-65 (64), Lh1 69-80 (74), Lh2 78-82 (79), Lh3 63-65 (64).

Ventral idiosoma (Fig. 1b): Length CXI 69-82 (75), width 42-48 (45), length CXII 58-67 (64), width 50-56 (53), length CXIII 79-88 (82), width 47-52 (50), C1C2 58-73 (62), C1-Mmcp 8-10 (9), C4-Pmcp 28-29 (28), C1 45-53 (49), C2 75-82 (79), C3 79-83 (81), C4 52-57 (54). Urstigma rounded (inner diameter $>10$ ). Expp present and relatively small, setae E1 + E2 absent. Exp relatively large, positioned medially between the only visible pair of insertions. Expp wider than long; length of excretory pore plate 13-14 (14), width 19-21 (20), V1 46-58 (52), V2 50-53 (51), V3 52-59 (56), V4 52-62 (57).

Gnathosoma: base 98-101 (99), length of chelicera (Fig. 1c) 94-98 (95), maximal width 33-36 (35), chela (dentate with two small teeth) 23-27 (25), P1 with one pinnated seta, P2 with two pinnated setae (Fig. 1d), length of P2 42-45 (44), width 32-34 (34), length of P3 31-34 (32), width 27-31 (30), P5 with two intense pinnated setae, claw 15-17 (16).

Legs: I-IIIL3 distinctly shorter than adjacent segments; empodial claw falciform; lateral claws slender and curved.

Leg I (Fig. 1e): total length 398-436 (418), length IL1 (1se) 34-38 (35), IL2 (2se) 59-62 (61), IL3 (5se) 30-33 (31), IL4 (5se, 1so, 1eu) 50-57 (54), IL5 (11se, 2so, 1eu) 80-83 (81), IL6 (21se, 1so, 1eu) 145-163 (155), claw 35-36 (35), height IL1 29-37 (33), IL2 2931 (30), IL3 26-27 (26), IL4 26-27 (26), IL5 26-28 (27), IL6 20-22 (21).

Leg II (Fig. 1f): total length 368-410 (391), length IIL1 (1se) 30-35 (34), IIL2 (2se) 58-60 (59), IIL3 (5se) 26-29 (27), IIL4 (5se, 1so, 1eu) 50-53 (51), IIL5 (10se, 2so, 1eu) 74-80 (77), IIL6 ( $21 \mathrm{se}, 1 \mathrm{so}, 1 \mathrm{eu}) 130-153$ (142), claw 35-35 (35), height IIL1 32-37 (34), IIL2 28-30 (29), IIL3 25-27 (26), IIL4 25-28 (27), IIL5 2627 (27), IIL6 21-23 (22). 
Leg III (Fig. 1g): total length 409-446 (428), length IIIL1 (1se) 36-38 (37), IIIL2 (1se) 53-60 (56), IIIL3 (5se) 28-31 (30), IIIL4 (4se, 1so) 57-60 (58), IIIL5 (10se, 1so) 90-94 (92), IIIL6 (20se) 145-163 (154), claw 36-37 (37), height IIIL1 33-36 (35), IIIL2 27-29 (28), IIIL3 25-27 (26), IIIL4 23-26 (25), IIIL5 22-23 (23), IIIL6 20-21 (20).

The larva of Panisus michaeli was previously described by Walter (1915) who reported the development of the later synonymous Thyas tridentina Maglio, 1909. He provided no illustrations but produced some measurements that were made on larvae that had not yet hatched. The given length of the leg segments, for example, are therefore probably distinctly smaller than for the $P$. michaeli larvae in the present study. However, apart from other ambiguous information, some characters were seen by Walter (1915); e.g. the two pectinated setae on P5 or the falciform claws. Interestingly, Walter (1915) was one of the first authors who noticed the occurrence of the urstigma between CXI and CXII in hydryphantoid water mite larvae. Lundblad (1927) illustrated the dorsal idiosoma and the palp. Like many authors (see especially for Protzia below), he overlooked the presence of the dorsal plate of $P$. michaeli. The only other described larvae of the genus belong to P. clypeolatus (Maglio, 1909) (Motas 1928). The given characters of $P$. clypeolatus show a distinct similarity to $P$. michaeli; in some measurements, $P$. clypeolatus is clearly smaller (e.g. leg length, length of some palpal segments). The larvae of $P$. $m i$ chaeli differ from the other Hydryphantidae larvae presented here with respect to the characteristic shape of the Expp, with only 1 pair of alveoli being located lateral of the Exp.

\section{Panisopsis curvifrons (Walter, 1907)}

Material examined: 4 larvae reared from females from spring no. 360 (NPB): characters of at most 3 larvae were measured.

Morphology: Idiosoma of larva ovate to moderately long (Fig. 2a, b); in undissected specimens, the enlarged heavy gnathosoma is striking; all idiosomal setae are smooth; length of idiosoma $(n=3)$ 200-218 (209), width 160-180 (168).

Dorsal idiosoma (Fig. 2a): Dorsal plate nearly as long as wide, with no distinctive constrictions. Length of Dp $(n=1) 65$, width 87, length of the anterior eye capsule 26, Mp2-Amdp 54, Mp1-Mp1 45, Mp2-Mp2 40, Lp1-Lp1 66, Lp2-Lp2 69, Mp1-Lp1 14, Mp2-Lp2 22, Mp1-Mp2 44, Lp1-Lp2 34, Mp1 72, Mp2 64, Lp1 62, Lp2 71, Hu 62, Mh1 74, Mh2 64, Mh3 62, Mh4 49, Lh1 56, Lh2 53, Lh3 54.
Ventral idiosoma (Fig. 2b): Expp present but not clearly delimited in its shape and nearly as long as wide; setae E1 + E2 absent and insertions of E2 only poorly visible. Insertions of E1 distinctly approached the Exp. Exp relatively large. Inner diameter of rounded urstigma small (about 10). Length CXI $(n=3)$ 70-92 (81), width 31-56 (43), length CXII 59-79 (17), width 43-51 (48), length CXIII 82-98 (91), width 49-56 (52), C1-C2 48-62 (55), C1-Mmcp 19-20 (20), C4-Pmcp 24-26 (25), C1 (n=1) 52, C2 54, C3 61, C4 48, length of Expp 14, width 16, E1-E1 13, V1 28, V2 35, V3 28, V4 32.

Gnathosoma $(n=3)$ : base relatively large (nearly as long as the width of the idiosoma); 150-178 (162), chelicera relatively heavy and with a distinct distally-dorsally elongated part and a relatively small and hook-like claw that is curved dorsally (Fig. 2c); length of chelicera 140-158 (149), maximal width 45-48 (46), chela 20-22 (21), P2 dorsally convex and distinctly off-set from the dorsal margin of P1 (Fig. 2d), length of P2 36-40 (38), width 44-45 (45), P2 and P3 with one slightly pinnated seta each and P3 with an additional trifurcate seta; length of P3 50-52 (51), width 37-44 (41), claw 16-19 (17).

Legs ( $\mathrm{n}=2)$ : I-IIIL2 relatively short and stout; empodial claw heavy and falciform; lateral claws fine, slender and curved. Leg segments relatively thick and thus appearing swollen.

Leg I (Fig. 2e): total length 386-419 (402), length IL1 (1se) 43-47 (45), IL2 (2se) 60-63 (62), IL3 (5se) 31-32 (32), IL4 (4se, 1so, 1eu) 52-56 (54), IL5 (10se, 2so, 1eu) 77-81 (79), IL6 (20se, 1so, 1eu) 123-140 (131), claw 27-28 (28), height IL1 33-34 (34), IL2 3741 (39), IL3 34-35 (35), IL4 32-34 (33), IL5 27-30 (29), IL6 22-23 (23).

Leg II (Fig. 2f): total length 326-344 (335), length IIL1 (1se) 40-40 (40), IIL2 (2se) 53-55 (54), IIL3 (5se) 25-28 (27), IIL4 (4se, 1so, 1eu) 37-42 (40), IIL5 (10se, 2so) 58-61 (60), IIL6 (20se, 1so, 1eu) 113-118 (115), claw 27-27 (27), height IIL1 32-32 (32), IIL2 30-30 (30), IIL3 27-27 (27), IIL4 26-26 (26), IIL5 24-25 (25), IIL6 22-24 (23).

Leg III (Fig. 2g): total length 344-369 (357), length IIIL1 (1se) 39-45 (42), IIIL2 (1se) 50-53 (52), IIIL3 (5se) 27-31 (29), IIIL4 (4se, 1so) 47-49 (48), IIIL5 (10se, 1so) 66-71 (69), IIIL6 (20se) 115-120 (118), claw 27-28 (28), height IIIL1 33-35 (34), IIIL2 31-31 (31), IIIL3 28-28 (28), IIIL4 26-27 (27), IIIL5 25-26 (26), IIIL6 22-23 (23).

The larva of $P$. curvifrons was accurately described by Walter (1915) and fragmentarily illustrated in Wal- 

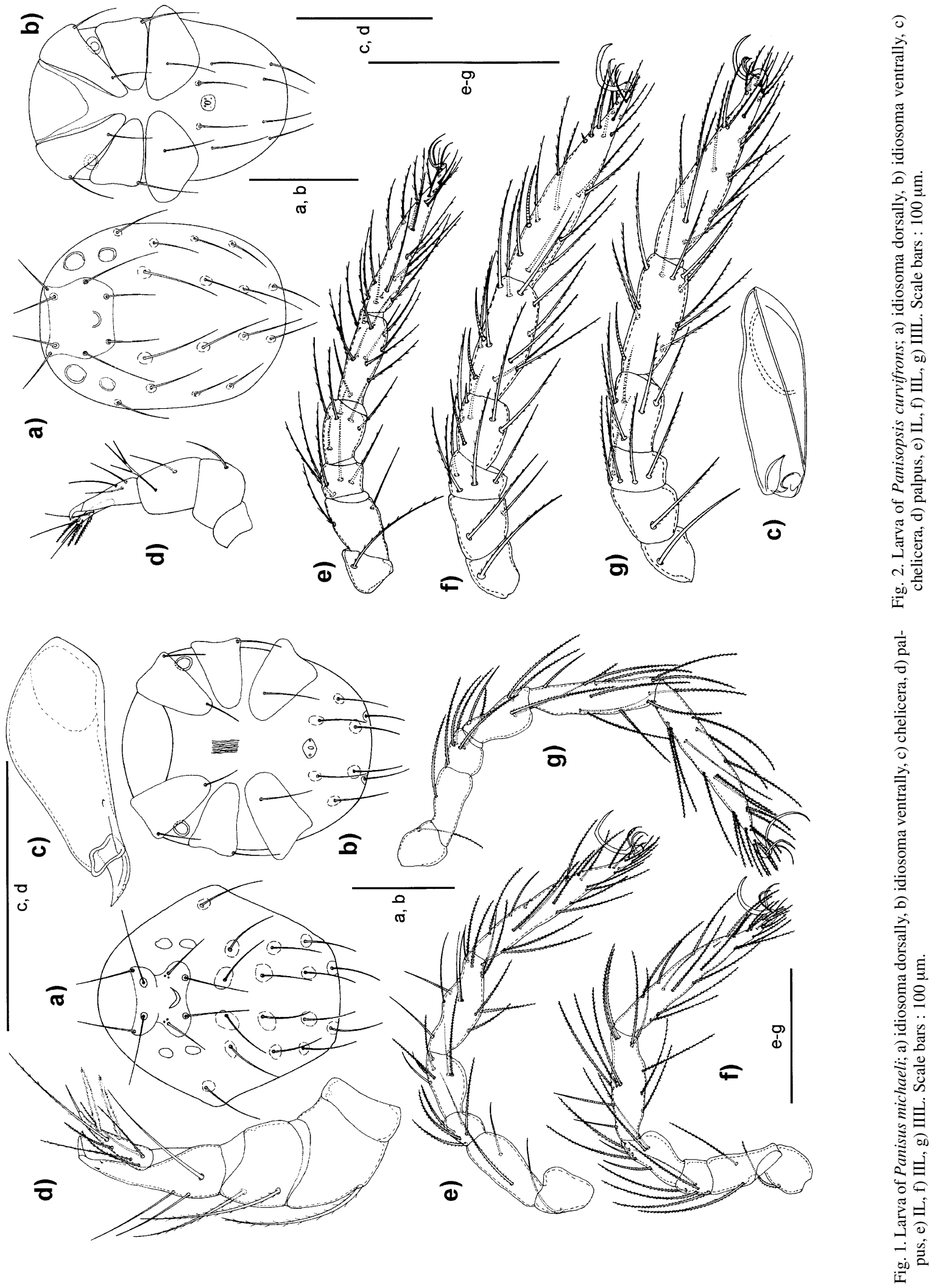
ter (1922a). Walter's descriptions agree with many of the characters presented here but he overlooked the urstigmata located between CXI and CXII, which are obviously smaller than, for example, those in Panisus michaeli. Walter also mentioned the large gnathosoma of the species, which is also to be found in the other described Panisopsis larvae (P. thori (Walter, 1907); Hubault 1927 and P. vigilans (Piersig, 1896); Viets 1928). Both descriptions are highly detailed and thus enable the characters that separate the Panisopsis larvae from the other hydryphantoid larvae described here to be easily recognised: in addition to the length of the gnathosomal base, these are, for example, the extraordinary shape of the chelicera and the multi-ended distal setae on P3.

\section{Thyas palustris Koenike, 1912}

Material examined: 9 larvae reared from a female collected by R. Gerecke (Tübingen, Germany) in a spring near the South-West German lake, the Mindelsee. Ovigourous females were collected at the $18^{\text {th }}$ of May 1997 and were reared in a microaquarium (room temperature and daylight). Ovipositioning occurred the next day and the larvae hatched after about 2-3 weeks: characters of 5 larvae were measured.

Morphology: Habitus of the idiosoma ovate and some of the idiosomal setae pinnate (Fig. 3a, b). Length of idiosoma 193-200 (197), width 155-183 (164).

Dorsal idiosoma (Fig. 3a): Dp slightly elongated, widest part median, length of Dp 62-75 (66), width 5865 (61), two distinct dots medial of Lp2 insertion. Diameter of the anterior eye capsule 16-18 (17), diameter of the posterior eye capsule 16-21 (18), diameter of the median eye 17-22 (19), all dorsal setae (with the exception of Mp1, Mp2, Lh2 and Lh3) pinnate, Mp2Amdp 59-63 (61), Mp1-Mp1 23-27 (25), Mp2-Mp2 26-29 (28), Lp1-Lp1 45-50 (47), Lp2-Lp2 52-57 (55), Mp1-Lp1 11-15 (14), Mp2-Lp2 20-23 (22), Mp1-Mp2 42-45 (44), Lp1-Lp2 33-36 (34), setae Mp1/2 distinct longer than setae Lp1/2, Mp1 118-155 (137), Mp2 148-160 (156), Lp1 62-69 (65), Lp2 53-58 (56), Hu 42-48 (45), Mh1 47-65 (59), Mh2 83-102 (92), Mh3 81-93 (87), Mh4 62-79 (72), Lh1 49-57 (53), Lh2 4348 (46), Lh3 38-42 (40).

Ventral idiosoma (Fig. 3b): Expp present but not clearly limited, setae E1 + E2 absent. Exp and insertions of setae E1 and E2 distinctly visible. All setae smooth, not pinnate. Urstigma small and slightly elongated (inner length <10). Length CXI 63-68 (65), width 40-43 (42), length CXII 53-62 (57), width 40-45 (42), length CXIII 68-70 (69), width 43-46 (44), C1C2 49-55 (53), C1-Mmcp 9-12 (11), C4-Pmcp 20-22 (21), C1-C4 46-51 (49), C1 36-42 (39), C2 46-51 (48),
C3 57-62 (59), C4 39-43 (41), V1 45-50 (47), V2 4449 (47), V3 49-53 (51), V4 52-55 (53).

Gnathosoma: base 82-85 (83), chelicera (Fig. 3c) 87-91 (88), chela (dentate with two small teeth) 22-25 (24), length P2 (Fig. 3d) 42-44 (43), width 19-19 (19), length P3 45-46 (45), width 7-9 (8), claw 15-17 (16).

Legs: empodial claws heavy and falciform; lateral claws slender and bristle-like.

Leg I (Fig. 3e): total length 305-333 (317), length IL1 (1se) 28-34 (31), IL2 (2se) 45-48 (46), IL3 (5se) 23-27 (24), IL4 (4se, 1so, 1eu) 46-52 (49), IL5 (10se, 2so, 1eu) 71-73 (72), IL6 (20se, 1so, 1eu) 92-99 (94), height IL1 31-32 (31), IL2 34-36 (35), IL3 34-37 (35), IL4 32-33 (32), IL5 22-25 (24), IL6 20-22 (21).

Leg II (Fig. 3f): total length 272-293 (281), length IIL1 (1se) 32-35 (33), IIL2 (2se) 36-39 (37), IIL3 (5se) 20-23 (21), IIL4 (4se, 1so, 1eu) 34-37 (36), IIL5 (10se, 2so) 60-63 (61), IIL6 (20se, 1 so, 1eu) 90-96 (93), height IIL1 28-30 (29), IIL2 23-26 (25), IIL3 23-26 (25), IIL4 22-24 (23), IIL5 21-22 (22), IIL6 21-22 (21).

Leg III (Fig. 3g): total length 292-314 (300), length IIIL1 (1se) 32-37 (34), IIIL2 (1se) 42-44 (43), IIIL3 (5se) 21-23 (22); relatively long seta on IIIL3, nearly reaching the centre of IIIL5, IIIL4 (4se, 1so) 38-40 (39), IIIL5 (10se, 1so) 65-68 (66), IIIL6 (20se) 94-102 (97), height IIIL1 29-31 (30), IIIL2 26-27 (26), IIIL3 24-26 (25), IIIL4 20-22 (21), IIIL5 19-21 (20), IIIL6 19-21 (20).

Thyas palustris is seen as a synonymous species to Thyas rivalis Koenike, 1912 (Lundblad 1962, Gerecke 1996). Only one description of the larva of T. palustris exists (Viets 1923a) but it is not accurate enough to compare with that of the present description. There are many descriptions of other Thyas larvae (see Smith \& Oliver 1986 for a review) but these are of differing quality. Detailed larval descriptions of species of the genus have been given by Wainstein (1980) and Tuzovskij (2000). Thyas rivalis larva can be distinguished from the other Hydryphantidae larvae described here by the indistinctly limited Expp, the long P5, the length of $\mathrm{Mp} 2$ and the small diameter of the urstigma.

Subfamily: Protziinae Koenike, 1909

Partnunia steinmanni Walter, 1906

Material examined: 8 larvae reared from females from spring no. 312 and from females from a collecting site between spring nos. 300 and 304 (NPB): characters of 5 larvae were measured.

Morphology: Habitus of the idiosoma moderately long (Fig. 4a, b). Length of idiosoma 205-218 (211), width 163-173 (167). 


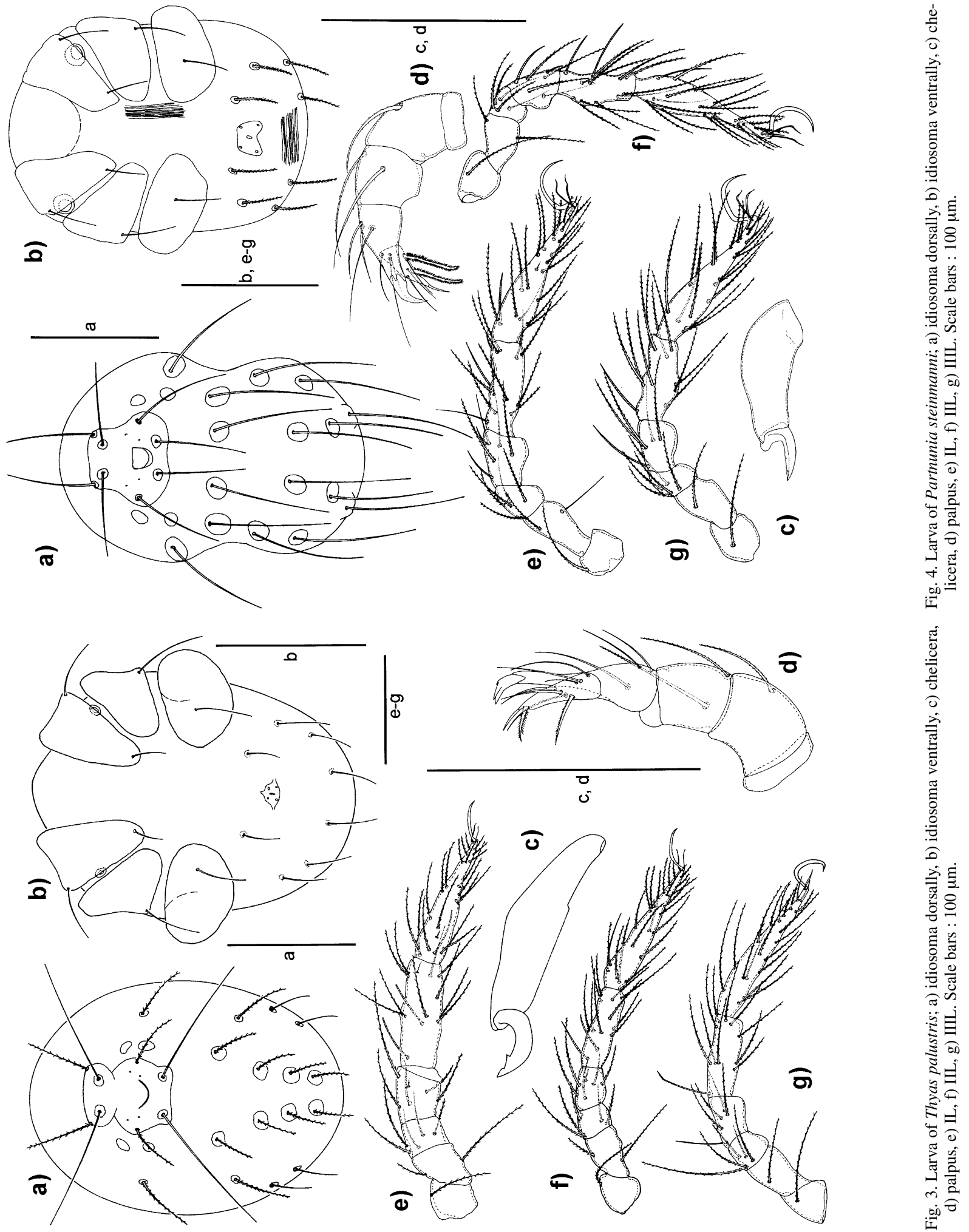


Dorsal idiosoma (Fig. 4a): All dorsal setae (with the exception of Mp1, Mp2) inconspiciously pinnated, setae Mh and Lh relatively long. Dp wider than long, anteriorly distinctly smaller than posteriorly, maximally broad posteriorly, length of dorsal plate 58-64 (61), width 73-78 (77), diameter of anterior eye capsule 17-19 (18), two distinct dots medial of Lp2 insertion. Mp2-Amdp 44-56 (49), Mp1-Mp1 18-23 (21), Mp2Mp2 19-28 (24), Lp1-Lp1 34-38 (24), Lp2-Lp2 51-59 (55), Mp1-Lp1 9-13 (11), Mp2-Lp2 19-21 (20), Mp1Mp2 32-41 (35), Lp1-Lp2 27-31 (30), Mp1 88-103 (94), Mp2 81-99 (94), Lp1 67-79 (72), Lp2 83-96 (89), Hu 84-91 (88), Mh1 88-96 (91), Mh2 88-100 (94), Mh3 89-98 (93), Mh4 85-89 (87), Lh1 77-81 (79), Lh2 80-88 (84), Lh3 77-83 (80).

Ventral idiosoma (Fig. 4b): Expp relatively large, distinctly limited, characteristically shaped by a posterior bay, setae E1 + E2 absent. Exp and insertions of setae E1 and E2 readily visible. V1-V4 pinnate, all other ventral setae smooth. Urstigma rounded and relatively large (interior diameter about 10), Length CXI 65-74 (69), width 41-52 (44), length CXII 65-71 (68), width 45-50 (47), length CXIII 70-78 (74), width 4547 (46), C1-C2 46-51 (49), C1-Mmcp 10-11 (10), C4Pmcp 24-26 (25), C1-C4 51-57 (53), C1 40-44 (42), C2 61-69 (64), C3 52-56 (54), C4 41-45 (43), length Expp 20-23 (22), width 28-33 (30), E1-E1 17-19 (18), E2-E2 17-19 (18), V1 51-59 (55), V2 48-52 (50), V3 52-55 (53), V4 61-66 (63).

Gnathosoma: base 85-88 (87), chelicera stout (Fig. 4c) 73-76 (75), chela (dentate with two small teeth) 23 27 (25), P2 with one pinnated seta, P3 with two pinnated setae, length P2 (Fig. 4d) 42-46 (44), width 27-31 (29), length P3 28-35 (32), width 28-30 (29), claw 1718 (18).

Legs: empodial claws heavy and elongated falciform; in lateral view, characteristically rectangularly curved at its base and distally; lateral claws slender and slightly curved.

Leg I (Fig. 4e): total length 331-358 (341), length IL1 (1se) 38-43 (40), IL2 (2se) 48-57 (51), IL3 (5se) 27-31 (29), IL4 (4se, 1so, 1eu) 46-48 (47), IL5 (10se, 2so, 1eu) 65-69 (67), IL6 (20se, 1 so, 1eu) 107-110 (108), height IL1 25-32 (28), IL2 28-31 (30), IL3 $27-$ 30 (28), IL4 28-31 (29), IL5 25-26 (26), IL6 24-27 (25), claw 33-35 (34).

Leg II (Fig. 4f): total length 309-341 (323), length IIL1 (1se) 38-42 (40), IIL2 (2se) 42-51 (47), IIL3 (5se) 26-32 (28), IIL4 (4se, 1so, 1eu) 41-46 (43), IIL5 (10se, 2so) 60-64 (62), IIL6 (20se, 1so, 1eu) 102-106 (104), height IIL1 28-33 (30), IIL2 26-28 (27), IIL3 24-26
(25), IIL4 26-29 (27), IIL5 24-26 (25), IIL6 25-26 (26), length claw 28-31 (30).

Leg III (Fig. 4g): total length 319-344 (331), length IIIL1 (1se) 40-43 (41), IIIL2 (1se) 44-49 (47), IIIL3 (5se) 23-29 (26), IIIL4 (4se, 1so) 43-48 (45), IIIL5 (10se, 1so) 62-66 (64), IIIL6 (20se) 107-109 (108), height IIIL1 27-31 (30), IIIL2 27-28 (27), IIIL3 25-28 (26), IIIL4 26-29 (27), IIIL5 24-26 (25), IIIL6 23-24 (23).

There has been no detailed description of larval $P$. steinmanni to date; the only information on a larva that was assigned to P. steinmanni is given by Münchberg (1954) but this work is of insufficient quality. The only other described larva of the genus is that of $P$. uchidai Imamura, 1950 (Imamura 1950). Although that description is also rather superficial, the main character that enables the separation of larval P. steinmanni from the other larvae of Hydryphantidae described here, viz. the characteristic shape of the excretory pore plate, is also present in $P$. uchidai.

\section{Protzia distinta Walter, 1922}

Material examined: 9 larvae reared from females from spring no. 360 (NPB); females and larvae from benthos of that spring: characters of 5 larvae were measured.

Morphology: Larva small, habitus of the idiosoma moderately elongated (Fig. 5a, b). Length of idiosoma 155-165 (161), width 125-133 (130).

Dorsal idiosoma (Fig. 5a): All setae, apart from Mh1, Mh2 and Lp1, distinctly pinnate. Dp longer than wide and anteriorly only slightly smaller than posteriorly, length of Dp 51-54 (53), width 31-36 (33), diameter of the anterior eye capsule 14-16 (15), Mp2Amdp 39-41 (40), Mp1-Mp1 19-21 (20), Mp2-Mp2 21-23 (22), Lp1-Lp1 36-37 (36), Lp2-Lp2 $43-45$ (44), Mp1-Lp1 8-10 (9), Mp2-Lp2 14-16 (15), Mp1-Mp2 29-33 (31), Lp1-Lp2 20-24 (22), Mp1 73-77 (75), Mp2 68-73 (71), Lp1 53-61 (57), Lp2 63-67 (65), Hu 59-63 (61), Mh1 57-60 (58), Mh2 61-63 (62), Mh3 57-61 (59), Mh4 48-53 (51), Lh1 52-58 (55), Lh2 53-59 (56), Lh3 51-55 (53).

Ventral idiosoma (Fig. 5b): Expp and setae E1 + E2 absent (or at least not visible), Exp only exceptionally visible. Setae V1-V4 pinnate. Urstigma relatively large (maximum interior diameter $>10$ ) and rounded. Length CXI 51-54 (53), width 31-36 (33), length CXII 52-57 (54), width 38-40 (39), length CXIII 63-68 (65), width 37-40 (38), C1-C2 38-41 (39), C1-Mmcp 9-11 (10), C4-Pmcp 19-22 (20), C1-C4 42-47 (44), C1 3841 (40), C2 50-54 (52), C3 47-56 (51), C4 46-51 (48), 
V1 43-46 (45), V2 46-48 (47), V3 53-57 (55), V4 5255 (54).

Gnathosoma: base 70-73 (71), chelicera (Fig. 5c) 65-69 (68), chela (dentate) 14-17 (16), P2 with one pinnated seta, P3 with two pinnated setae, length P2 (Fig. 5d) 35-37 (36), width 26-30 (28), length P3 27-32 (29), width 23-27 (25), claw 12-14 (13).

Legs: empodial claw heavy and falciform and, in lateral view, distinctly curved; lateral claws slender and slightly curved.

Leg I (Fig. 5e): total length 306-323 (314), length IL1 (1se) 31-33 (32), IL2 (2se) 40-47 (43), IL3 (5se) 24-26 (25), IL4 (4se, 1so, 2eu) 48-49 (48), IL5 (10se, 2so, 1eu) 65-66 (65), IL6 (20se, 1so, 1eu) 98-102 (101), height IL1 26-31 (29), IL2 28-31 (29), IL3 2526 (25), IL4 26-28 (27), IL5 22-25 (23), IL6 21-23 (22), length claw 30-33 (31).

Leg II (Fig. 5f): total length 285-306 (295), length IIL1 (1se) 30-35 (33), IIL2 (2se) 38-42 (39), IIL3 (5se) 23-26 (24), IIL4 (4se, 1so, 1eu) 39-42 (40), IIL5 (10se, 1so) 58-61 (60), IIL6 (20se, 1so, 1eu) 97-100 (99), height IIL1 24-28 (27), IIL2 25-26 (25), IIL3 22-24 (23), IIL4 23-26 (24), IIL5 21-23 (22), IIL6 23-27 (24), length claw 30-31 (30).

Leg III (Fig. 5g): total length 297-320 (308), length IIIL1 (1se) 34-36 (35), IIIL2 (1se) 37-43 (40), IIIL3 (5se) 21-25 (24), IIIL4 (4se, 1so) 42-43 (42), IIIL5 (10se, 1so) 60-64 (62), IIIL6 (20se) 103-109 (105), height IIIL1 25-30 (27), IIIL2 24-25 (25), IIIL3 22-25 (24), IIIL4 22-24 (23), IIIL5 20-21 (21), IIIL6 20-21 (20), length claw 32-33 (32).

The larva of $P$. distincta was previously undescribed. Other descriptions of Protzia larvae refer to $P$. eximia (Protz, 1896) (see Martin 2000 for references) and $P$. brevipalpis Maglio, 1909 (Motas 1929). With the exception of the work of Jones (1967), in all these descriptions, the presence of the dorsal plate in the larvae was probably overlooked, a mistake that could definitively be clarified, by the author, for the larvae of $P$. eximia of the North German population. In Protzia larvae, the dorsal plate seems not to be clearly delimited from the dorsal integument. In Smith et al. (2001), contradictory characters of a Protzia sp. larva are illustrated. This larva has a distinct Expp but is lacking a Dp. The P. distincta larvae differ from the other larval hydryphantoids described here with respect to the absence of a excretory pore plate and the lack of alveoli of setae E1 and E2.

Subfamily: Tartarothyadinae Viets, 1924

Tartarothyas romanica Husiatinschi, 1937
Material examined: 4 larvae reared from females from a collecting site between spring nos. 300 and 304 (NPB): characters of at most 4 larvae were measured.

Morphology: Habitus of the idiosoma slightly ovate (Fig. 6a, b). Length of idiosoma $(n=4)$ 210-218 (213), width 160-170 (164).

Dorsal idiosoma (Fig. 6a): All setae, apart from Mh1 and Mh2, pinnate. Dp nearly as long as wide, anteriorly smaller than posteriorly, maximum width immediately posterior of the insertions of seta Lp2, length of Dp $(n=2) 74-80$ (77), width 80-81 (81), median eye inconspicuous but present, length of anterior eye capsule 16-17 (17), Mp2-Amdp 64-72 (68), Mp1-Mp1 2427 (26), Mp2-Mp2 49-51 (50), Lp1-Lp1 46-50 (48), Lp2-Lp2 67-68 (68), Mp1-Lp1 15-18 (17), Mp2-Lp2 23-24 (24), Mp1-Mp2 48-53 (51), Lp1-Lp2 35-39 (37), setae Mp1/2 distinct longer than setae Lp1/2, Mp1 (n=1) 185, Mp2 (n=2) 170-183 (176), Lp1 (n=1) 62, Lp2 (n=2) 61-63 (62), Hu (n=1) 68, Mh1 72, Mh2 95, Mh3 94, Mh4 76, Lh1 73, Lh2 85, Lh3 72.

Ventral idiosoma (Fig. 6b): Expp present but indistinctly limited, setae E1 + E2 absent, Exp and insertions of setae E1 and E2 only poorly visible. Setae V1V4 smooth. Urstigma large and slightly elongated (maximum interior diameter about 15). Length CXI $(n=2)$ 72-76 (74), width 41-46 (44), length CXII 69-72 (71), width 35-39 (37), length CXIII 78-86 (82), width 45-56 (51), C1-C2 56-60 (58), C1-Mmcp 11-11 (11), C4-Pmcp 15-19 (17), C1 58-58 (58), C2 (n=1), 71, C3 $(n=2) 56-79$ (68), C4 48-54 (51), length of Expp $(n=1)$ 10 , width 25, E1-E1 10, E2-E2 12, V1 $(\mathrm{n}=2)$ 43-45 (44), V2 45-58 (52), V3 42-45 (44), V4 42-44 (43).

Gnathosoma $(n=3)$ : base $84-88(86)$, ventrodistal setae of the gnathosomal base (Hy2) relatively long (about 25), length of chelicera (Fig. 6c) 82-84 (83), maximal width 23-25 (24), chela (dentate with two small teeth) 24-26 (25), P2 with one pinnated seta and P3 with two pinnated setae, length of P2 (Fig. 6d) 4041 (40), width 29-30 (29), length of P3 25-29 (26), width 30-30 (30), claw 19-20 (19).

Legs: Empodial claw heavy and falciform; lateral claws slender and curved. Remarkably long setae on IIL3 and IIIL3 (longer than the dorsal length of the leg segments 3-5), IL2 and IIIL2 relatively short.

Leg I ( $n=2)$ (Fig. 6e): total length 349-379 (364), length IL1 (1se) 33-36 (35), IL2 (2se) 45-50 (48), IL3 (5se) 32-34 (33), IL4 (4se, 1so, 1eu) 46-50 (48), IL5 (10se, 2so, 1eu) 73-79 (76), IL6 (20se, 1so, 1eu) 120130 (125), claw 32-32 (32), height IL1 30-35 (33), IL2 31-33 (32), IL3 31-32 (32), IL4 35-38 (37), IL5 24-27 (26), IL6 23-25 (24). 


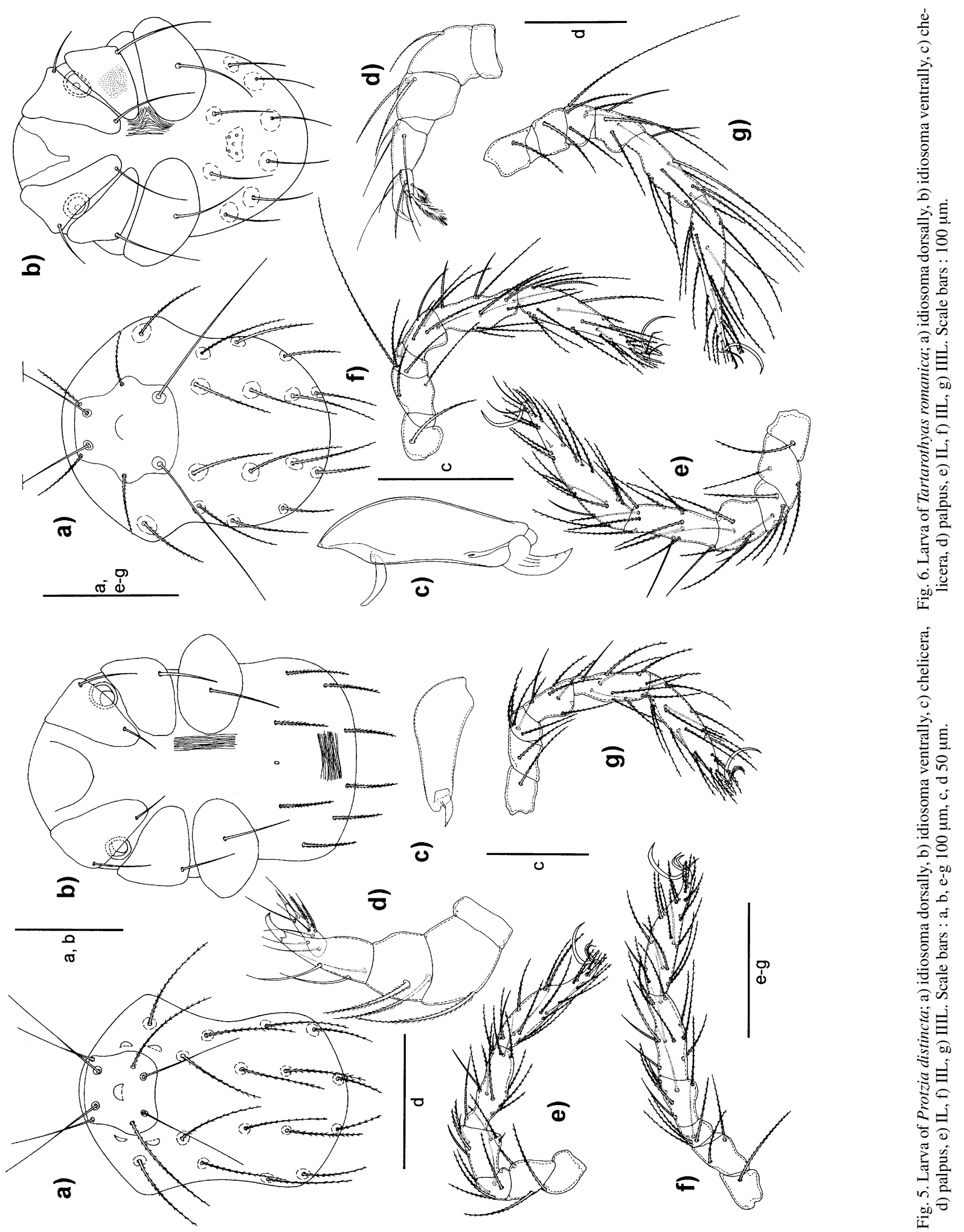


Leg II (n=3) (Fig. 6f): total length 309-332 (319), length IIL1 (1se) 32-37 (34), IIL2 (2se) 42-42 (42), IIL3 (5se) 27-30 (28), IIL4 (4se, 1so, 1eu) 36-39 (37), IIL5 (10se, 2so) 62-66 (64), IIL6 (20se, 1so, 1eu) 110118 (113), height IIL1 28-32 (30), IIL2 27-29 (28), IIL3 25-26 (26), IIL4 25-28 (27), IIL5 24-25 (25), IIL6 20-25 (23).

Leg III (Fig. 6g): total length 324-350 (337), length IIIL1 (1 se) 35-43 (40), IIIL2 (1 se) 40-46 (42), IIIL3 (5se) 27-28 (27), IIIL4 (4se, 1so) 39-39 (39), IIIL5 (10se, 1so) 65-71 (68), IIIL6 (20se) 118-123 (121), height IIIL1 29-32 (30), IIIL2 28-30 (29), IIIL3 28-29 (28), IIIL4 26-28 (27), IIIL5 24-26 (25), IIIL6 22-22 (22).

The description of larval $T$. romanica is the only description of a larva of the genus. For two hitherto undescribed North American Tartarothyas species, the parasitization of chironomids is reported but without any information on the larval morphology (Smith 1991). One character of $T$. romanica that is shared by Thyas palustris is that setae Mp1/2 are much longer than setae Lp1/2. In the key of Smith et al. (2001), the reduction of the medial eye in Tartarothyas is presented as a character for the subfamily Tartarothyadinae, although a medial eye is illustrated. Therefore, this character seems to be inappropriate. The considerable length of the setae on IIL3 and IIIL3 enable a separation of the larva from the other species of Hydryphantidae described here.

\section{Family: Sperchontidae Thor, 1900}

Diagnosis: Dorsal plate mostly large, covering more than half the length of the idiosoma and bearing 4 pairs of setae; lateral eyes on each side borne on an eye plate; coxal plates I to III separate, plate III in most cases very large; plates I-III with 3 or 4 pairs of coxal setae (C3 on CXII present or absent); chelicerae small, basal segments separated from each other; chela dentate; palpal segment 4 and 5 short, P5 thumb-like; some setae on palpal segments very large; legs I to III five-segmented and each with three heavy claws; fusion line of former basifemur and telofemur present on legs I to III; leg segments 5 broad distally; eupathidium present on distal leg segment of legs I, II and III; solenidia on leg segments 3 to 5 of legs I and II very thin and placed at the distal end of the segment.

Wainstein (1980) reported the chaetotaxy of the legs of $S$. clupeifer: IL1 1se, IL2 7se, IL3 4se+1so, IL4 $9 \mathrm{se}+2 \mathrm{so}+1 \mathrm{eu}$, IL5 $13 \mathrm{se}+1 \mathrm{so}+2 \mathrm{eu}$; IIL1 1se, IIL2 7se, IIL3 4se+1so, IIL4 9se+2so+1eu, IIL5 13se+1so+2eu; IIIL1 1se, IIIL2 6se, IIIL3 4se+1so; IIIL4 9se+1so, IIIL5 $13 \mathrm{se}+1 \mathrm{eu}$. This may reflect the typical setation of Sperchon larvae, although for most of the sperchon- tid larvae described below, the eupathidia were not clearly seen. In contrast to Prasad \& Cook (1972), Wainstein (1980) and the present observations, Smith (1982) found North American Sperchon larvae with 16 setae (se+so) on segments IIL4/5 and 14 setae on IIIL5.

\section{Sperchon mutilus Koenike, 1895}

Material examined: 10 larvae reared from females from spring nos. 312 and 360 (NPB): characters of 5 larvae were measured.

Morphology: Habitus of the idiosoma moderately ovate (Fig. 7a, b). Length of idiosoma 258-276 (261), width 205-215 (209).

Dorsal idiosoma (Fig. 7a): Dp large, caudally broadened and covering nearly the complete dorsal idiosoma, lineated. Length of Dp 238-253 (247), width 175185 (182), length of anterior eye capsule 13-14 (13), Mp2-Amdp 47-54 (49), Mp1-Mp1 56-62 (58), Mp2Mp2 44-50 (47), Lp1-Lp1 38-42 (40), Lp2-Lp2 84-88 (86), Mp1-Lp1 10-12 (11), Mp2-Lp2 25-29 (27), Lp1Mp2 37-43 (40), Mp1-Lp2 19-23 (22), Mp1 27-32 (30), Mp2 33-38 (36), Lp1 52-58 (56), Lp2 112-118 (115), Hu 68-87 (76), Mh1 98-103 (100), Mh2 92-95 (94), Mh3 82-87 (85), Mh4 52-65 (61), Lh1 95-103 (97), Lh2 88-92 (90), Lh3 53-73 (62).

Ventral idiosoma (Fig. 7b): A chitinous structure lies anterior of setae V1. Length CXI 88-100 (93), width 37-40 (38), length CXII 80-85 (82), width 59-76 (68), length CXIII 110-120 (113), width 82-92 (86), urstigma elongated, C1-C2 45-51 (47), C1-Mmcp 28-32 (31), C4-Pmcp 98-102 (99), C1-C4 50-54 (52), C1 65-72 (67), C2 69-82 (78), C3 41-49 (46), C4 65-77 (73), length Expp 14-17 (15), width 14-16 (15), E1-E1 6-8 (7), E2-E2 10-13 (12), E1 14-19 (17), E2 14-21 (18), V1 63-70 (66), V2 45-72 (59), V3 61-65 (63), V4 $50-57$ (54).

Gnathosoma: base 95-98 (96), length chelicera (Fig. 7c) 81-83 (82), width 20-22 (20), chela 20-22 (21), length P2 (Fig. 7d) 40-43 (42), width 29-31 (30), length P3 29-32 (30), width 26-30 (27), claw 18-20 (19).

Legs: Leg segments I-IIIL3+4 and IIIL5 distinctly lineated.

Leg I (Fig. 7e): total length 288-308 (299), length IL1 (1se) 37-40 (39), IL2 (7se) 59-62 (61), IL3 (4se, 1so) 60-62 (61), IL4 (9se, 1so) 65-69 (67), IL5 (13se, 1so) 67-75 (71), height IL1 26-29 (28), IL2 28-30 (29), IL3 26-28 (27), IL4 22-25 (23), IL5 18-20 (19).

Leg II (Fig. 7f): total length 307-329 (319), length IIL1 (1se) 44-45 (44), IIL2 (7se) 58-61 (60), IIL3 (4se, 1so) 61-66 (64), IIL4 (9se, 2so) 71-77 (74), IIL5 (13se, 

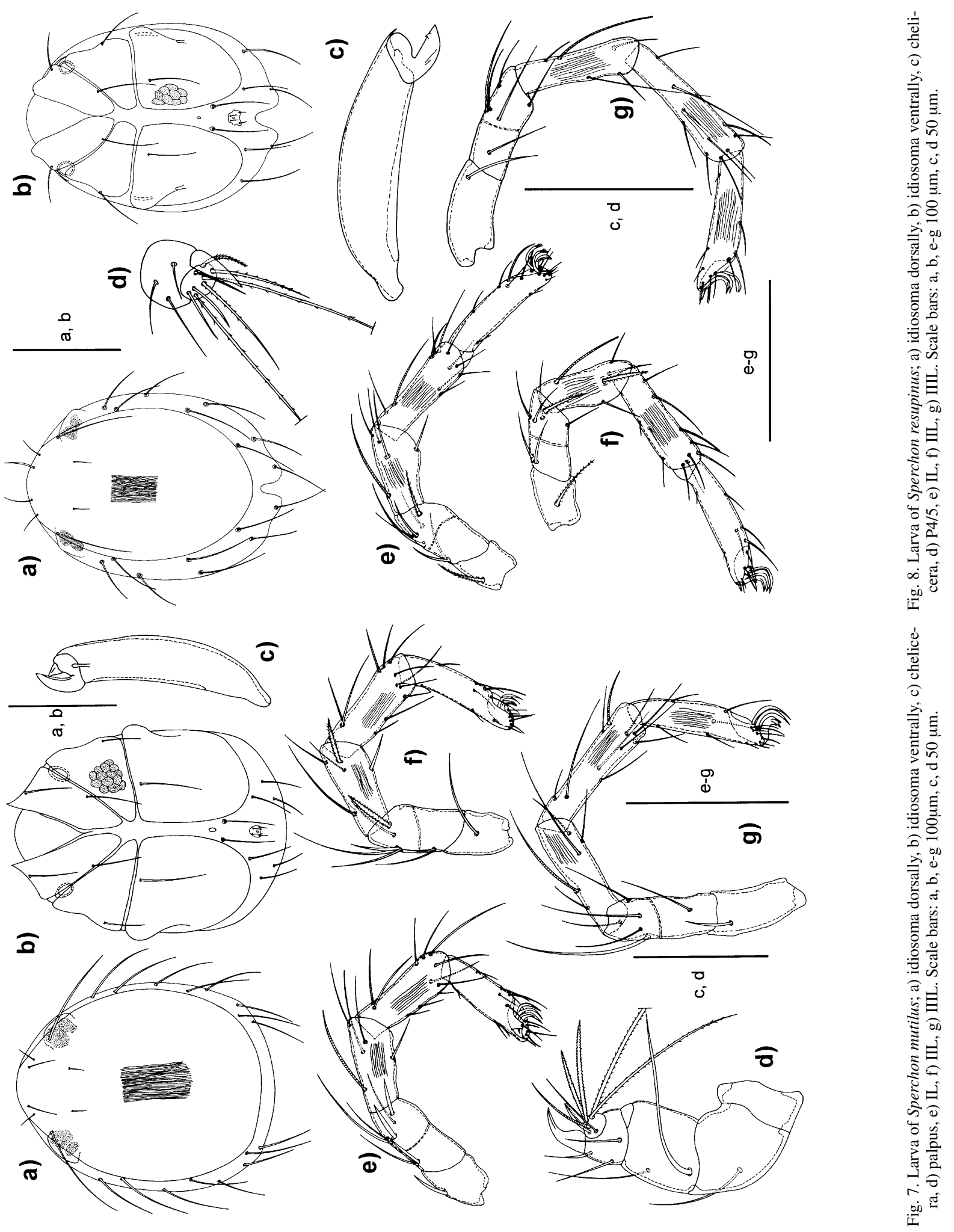
1so) 73-80 (77), height IIL1 27-31 (29), IIL2 27-29 (28), IIL3 25-26 (25), IIL4 21-23 (22), IIL5 18-19 (19).

Leg III (Fig. 7g): total length 379-413 (397), length IIIL1 (1se) 69-75 (72), IIIL2 (6se) 67-70 (68), IIIL3 (4se, 1so) 79-83 (80), IIIL4 (9se, 1so) 84-95 (90), IIIL5 (13se) 80-90 (86), height IIIL1 28-30 (29), IIIL2 25-26 (25), IIIL3 20-23 (22), IIIL4 21-22 (22), IIIL5 $17-19$ (18)

To date, there has been no description of the larva of $S$. mutilus. Characters that enable the taxonomic separation of $S$. mutilus from the other Sperchon species described here are, for example, the relatively broad Dp (length/width $<1,4)$ or the extensive length of Lp2 (> $110 \mu \mathrm{m})$.

\section{Sperchon resupinus Viets, 1922}

Material examined: 12 larvae reared from females from spring nos. 312 and 390 (NPB): characters of 5 larvae were measured.

Morphology: Habitus of the idiosoma moderately ovate; in non-engorged specimens, caudal idiosoma with a distinct indentation (Fig. 8a, b). Length of idiosoma 258-263 (260), width 180-193 (184).

Dorsal idiosoma (Fig. 8a): Dp relatively large, small-ovate and lineated. Length of Dp 223-233 (228), width 145-155 (150), length of anterior eye capsule 10-12 (11), Mp2-Amdp 43-47 (45), Mp1-Mp1 54-58 (56), Mp2-Mp2 47-51 (49), Lp1-Lp1 32-38 (35), Lp2Lp2 81-87 (84), Mp1-Lp1 10-12 (11), Mp2-Lp2 24-28 (26), Lp1-Mp2 36-43 (39), Mp1-Lp2 18-22 (21), Mp1 25-28 (26), Mp2 25-32 (29), Lp1 45-53 (50), Lp2 8793 (90), Hu 73-82 (76), Mh1 83-93 (89), Mh2 84-87 (85), Mh3 71-78 (74), Mh4 59-67 (63), Lh1 75-83 (80), Lh2 72-80 (75), Lh3 53-62 (58).

Ventral idiosoma (Fig. 8b): A small chitinous structure lies anterior of the setae V1. Length CXI 82-87 (84), width 37-42 (40), length CXII 75-78 (77), width 66-70 (68), length CXIII 118-128 (124), width 80-84 (82), urstigma rounded, C1-C2 47-50 (48), C1-Mmcp 22-24 (23), C4-Pmcp 95-103 (100), C1-C4 37-47 (42), C1 51-62 (55), C2 62-78 (71), C3 64-68 (66), C4 4548 (47), length Expp 16-19 (17), width 15-17 (16), E1E1 8-8 (8), E2-E2 9-11 (10), E1 13-21 (18), E2 20-24 (22), V1 53-62 (58), V2 49-53 (51), V3 62-72 (66), V4 67-72 (69).

Gnathosoma: base 72-78 (74), length chelicera (Fig. 8c) 68-76 (72), chela 17-20 (18), length P2 35-36 (35), width 27-28 (27), length P3 28-29 (28), width 23-26 (25), the two long setae of P5 have nearly the same length (Fig. 8d), claw 18-22 (19).
Legs: Leg segments I-IIIL3+4 and IIIL5 lineated, but not pronounced.

Leg I (Fig. 8e): total length 291-304 (297), length IL1 (1se) 34-36 (35), IL2 (7se) 58-63 (59), IL3 (4se, 1so) 59-61 (60), IL4 (9se, 2so) 67-69 (68), IL5 (13, 1so) 73-75 (74), height IL1 26-29 (27), IL2 28-29 (28), IL3 24-26 (25), IL4 20-23 (22), IL5 18-19 (19).

Leg II (Fig. 8f): total length 306-320 (313), length IIL1 (1se) 41-43 (42), IIL2 (7se) 55-58 (57), IIL3 (4se, 1so) 59-63 (62), IIL4 (9se, 2so) 72-74 (73), IIL5 (13se, 1so) 79-82 (80), height IIL1 27-28 (27), IIL2 26-28 (27), IIL3 22-24 (23), IIL4 20-22 (21), IIL5 17-19 (18).

Leg III (Fig. 8g): total length 381-399 (390), length IIIL1 (1se) 59-64 (61), IIIL2 (6se) 66-68 (67), IIIL3 (4se, 1so) 78-81 (80), IIIL4 (9se, 1so) 90-96 (93), IIIL5 (12se) 88-90 (89), height IIIL1 27-29 (28), IIIL2 22-25 (24), IIIL3 21-22 (21), IIIL4 20-22 (21), IIIL5 16-19 (17).

The larval description of $S$. resupinus is the first for this species. The distinct indentation of the posterior idiosoma in Sperchon larvae has also been shown for S. squamosus (Ullrich 1976) and is obviously typical for larvae of this species that have not yet taken in food. Characters of the Dp (e.g. length/high > 1,4, Lp2 $<100 \mathrm{~mm}$ ) enable a separation of the larva from the other sperchontid larvae presented here.

\section{Sperchon thienemanni Koenike, 1907}

Material examined: 12 larvae reared from females from a collecting site positioned between spring nos. 300 and no. 304 (NPB): characters of 5 larvae were measured.

Morphology: Larva relatively small, habitus of the idiosoma moderately elongated (Fig. 9a, b). Length of idiosoma 208-215 (212), width 140-150 (146).

Dorsal idiosoma (Fig. 9a): Dp posteriorly narrowed, Dp lineated. Length of Dp 200-208 (202), width 95105 (101), length of anterior eye capsule 8-9 (8), Mp2Amdp 40-43 (42), Mp1-Mp1 54-57 (56), Mp2-Mp2 33-39 (36), Lp1-Lp1 39-45 (42), Lp2-Lp2 71-75 (73), Mp1-Lp1 10-11 (10), Mp2-Lp2 22-27 (24), Lp1-Mp2 35-37 (36), Mp1-Lp2 15-27 (18), Mp1 28-32 (30), Mp2 29-33 (31), Lp1 32-38 (34), Lp2 98-104 (101), Hu 83-88 (85), Mh1 81-88 (85), Mh2 75-82 (78), Mh3 49-53 (51), Mh4 34-40 (38), Lh1 75-82 (78), Lh2 6470 (67), Lh3 47-52 (49).

Ventral idiosoma (Fig. 9b): A chitinous structure anterior of the setae V1 is completely absent or, if present, is only small. Length CXI 81-83 (82), width 3537 (36), length CXII 63-68 (64), width 48-54 (50), 

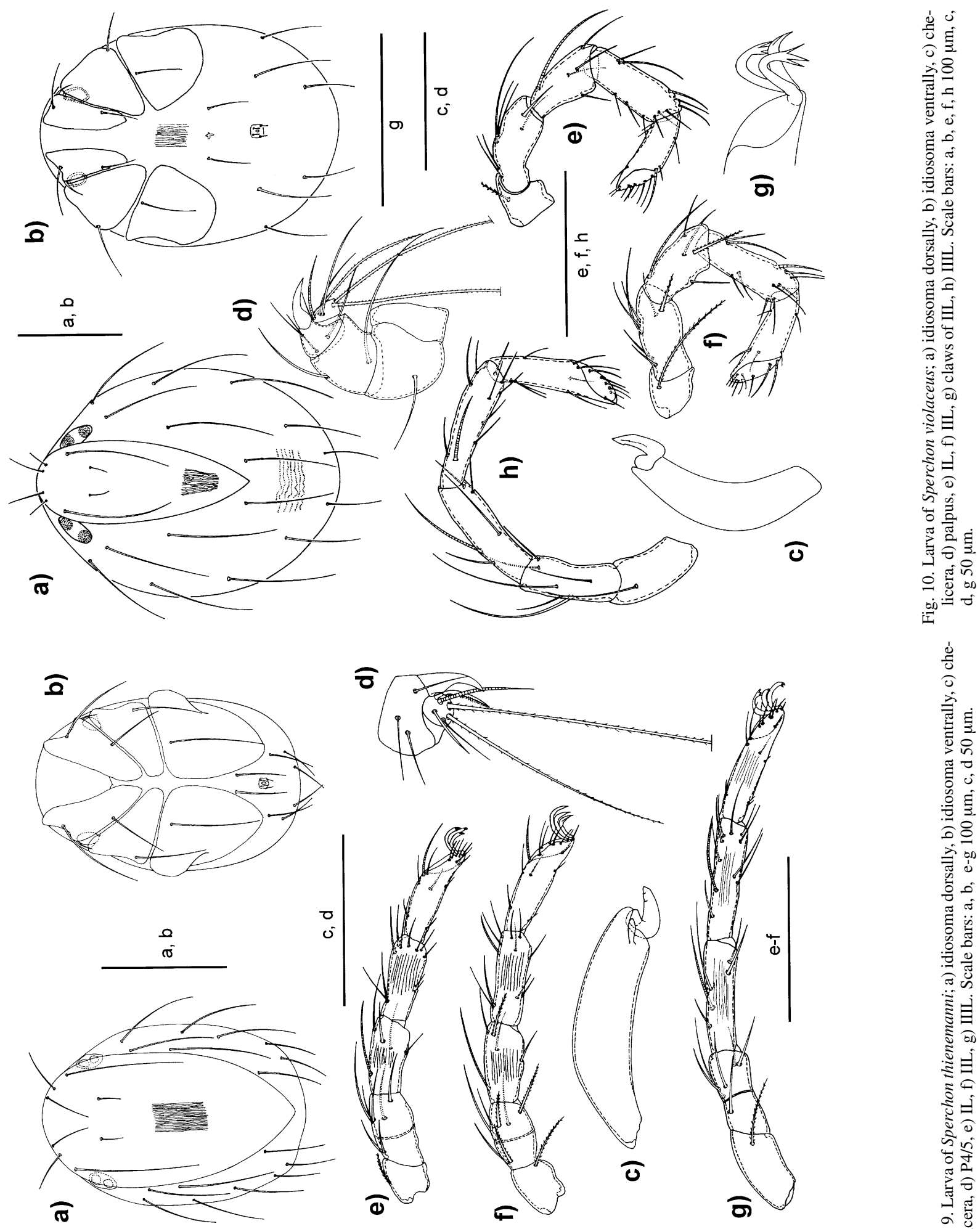

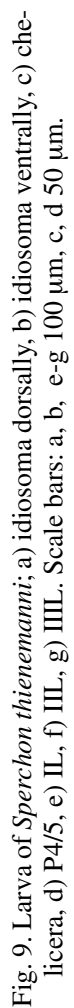


length CXIII 85-89 (87), width 68-72 (71), urstigma elongated, C1-C2 37-42 (40), C1-Mmcp 23-28 (26), C4-Pmcp 70-75 (73), C1-C4 43-48 (46), C1 51-64 (58), C2 67-81 (74), C3 43-61 (49), C4 58-77 (64), length Expp 8-13 (10), width 8-12 (10), E1-E1 5-7 (6), E2-E2 6-10 (8), E1 12-14 (13), E2 15-16 (15), V1 3842 (40), V2 35-40 (37), V3 28-36 (33), V4 22-28 (25).

Gnathosoma: base 78-84 (81), chelicera (Fig. 9c) 69-72 (71), chela 16-20 (18), length P2 37-39 (38), width 30-31 (30), length P3 28-29 (28), width 25-28 (27), claw (Fig. 9d) 17-19 (18).

Legs: Leg segments I-IIIL3+4 and IIIL5 moderately lineated.

Leg I (Fig. 9e): total length 243-273 (253), length IL1 (1se) 31-37 (33), IL2 (7se) 48-52 (49), IL3 (4se, 1so) 49-52 (50), IL4 (9se, 2so) 53-61 (55), IL5 (13se, 1so) 62-71 (64), height IL1 24-27 (25), IL2 24-27 (26), IL3 23-24 (23), IL4 21-22 (21), IL5 17-18 (18).

Leg II (Fig. 9f): total length 261-281 (272), length IIL1 (1se) 34-37 (35), IIL2 (7se) 48-54 (52), IIL3 (4se, $1 \mathrm{so}) 52-55$ (53), IIL4 (9se, 2so) 59-63 (61), IIL5 (13se, 1so) 68-72 (71), height IIL1 24-27 (25), IIL2 24-25 (25), IIL3 22-23 (22), IIL4 20-20 (20), IIL5 17-18 (18).

Leg III (Fig. 9g): total length 331-347 (339), length IIIL1 (1se) 57-61 (59), IIIL2 (6se) 54-56 (55), IIIL3 (4se, 1so) 67-71 (69), IIIL4 (9se, 1so) 74-78 (76), IIIL5 (13se) 79-81 (80), height IIIL1 25-26 (25), IIIL2 22-24 (23), IIIL3 20-22 (21), IIIL4 19-20 (19), IIIL5 15-17 (16).

Until the separation as an individual species by Bader (1974), Sperchon thienemanni was seen as a form or a subspecies of S. glandulosus (e.g. Viets 1936). The first description of a larva of the former S. glandulosus thienemanni was given by Lundblad (1927). A detailed description of the larvae of both $S$. thieneman$n i$ and $S$. glandulosus was only given in the unpublished part of the thesis of Ullrich (1976); therefore, a re-description with additional characters is presented here. According Ullrich (1976), the larva of S. thienemanni differs from the closely related $S$. glandulosus: in comparison with $S$. glandulosus, C3 is short (about $20 \mu \mathrm{m}$ ) and the lineation of the legs is barely visible. The present description of $S$. thienemanni agrees with that of Ullrich to a large extent but his larva differs in having a larger Dp (length/width 225/150 $\mu \mathrm{m}$ ) and in a more distinct lineation of the leg segments.

With respect to the other Sperchon larvae described here, $S$. thienemanni differs by its small Dp and the distance Mp1-Mp1, which is greater than $50 \mu \mathrm{m}$.

\section{Sperchon violaceus Walter, 1944}

Material examined: 7 larvae reared from females from spring no. 360 (NPB): characters of 5 larvae were measured.

Morphology: Habitus of the idiosoma moderately rounded (Fig. 10a, b). Length of idiosoma 208-283 (244), width 158-228 (192).

Dorsal idiosoma (Fig. 10a): Dp short and narrow and not clearly delimited from the dorsal integument, anteriorly rounded, posteriorly tapering; covering about a third of the dorsal idiosoma, Dp lineated, length of Dp 168-200 (179), width 65-83 (76), length of eye plate 27-35 (30), width 17-22 (19), Mp2-Amdp 40-55 (47), Mp1-Mp1 38-44 (41), Mp2-Mp2 23-29 (25), Lp1-Lp1 26-30 (28), Lp2-Lp2 53-62 (56), Mp1-Lp1 7-9 (8), Mp2-Lp2 23-29 (25), Lp1-Mp2 39-43 (41), Mp1-Lp2 12-16 (14), Mp1 30-37 (34), Mp2 30-34 (32), Lp1 5763 (60), Lp2 102-109 (106), Hu 90-105 (99), Mh1 98110 (103), Mh2 93-100 (97), Mh3 80-108 (94), Mh4 58-88 (71), Lh1 75-95 (86), Lh2 80-88 (83), Lh3 70-90 (83).

Ventral idiosoma (Fig. 10b): A small, chitinous and differently shaped structure is often located anterior of Expp and between the setae V1. Urstigma elongated. Length CXI 78-82 (79), width 32-38 (35), length CXII 70-75 (72), width 53-60 (56), CXIII relatively short, length CXIII 70-75 (73), width 85-88 (87), C1-C2 41-45 (43), C1-Mmcp 19-22 (21), C4-Pmcp 68-76 (71), C1-C4 44-46 (45), C1 42-47 (44), C2 52-83 (65), C3 69-76 (73), C4 58-65 (60), Expp small and nearly as long as wide, length Expp 12-14 (13), width 13-14 (13), E1-E1 6-7 (6), E2-E2 10-11 (10), E1 13-20 (15), E2 16-24 (19), V1 48-62 (55), V2 66-72 (69), V3 60-63 (62), V4 65-81 (71).

Gnathosoma: base 80-84 (82), chelicera (Fig. 10c) 60-68 (65), chela 15-18 (16), length P2 (Fig. 10d) 3746 (40), width 25-27 (26), length P3 25-27 (26), width 23-26 (25), claw 15-16 (16).

Legs: lineation of legs (I-IIIL3+4) poorly visible.

Leg I (Fig. 10e): total length 268-289 (277), length IL1 (1se) 36-40 (37), IL2 (7se) 54-58 (56), IL3 (4se, 1so) 52-57 (55), IL4 (9se, 2so) 63-66 (64), IL5 (13se, 1so) 63-68 (65), height IL1 26-29 (27), IL2 26-28 (27), IL3 25-28 (27), IL4 22-22 (22), IL5 20-21 (20).

Leg II (Fig. 10f, g): total length 275-293 (283), length IIL1 (1se) 38-42 (39), IIL2 (7se) 54-58 (56), IIL3 (4se, 1so) 54-57 (55), IIL4 (9se, 2so) 63-66 (65), IIL5 (13se, 1so) 66-70 (67), height IIL1 27-29 (28), IIL2 25-28 (27), IIL3 24-26 (25), IIL4 21-23 (22), IIL5 19$21(20)$. 
Leg III (Fig. 10h): total length 348-362 (356), length IIIL1 (1 se) 60-62 (61), IIIL2 (6se) 59-62 (61), IIIL3 (4se, 1so) 72-75 (73), IIIL4 (9se, 1so) 81-83 (82), IIIL5 (13se) 76-80 (78), height IIIL1 24-28 (26), IIIL2 25-26 (25), IIIL3 22-24 (23), IIIL4 20-22 (21), IIIL5 19-20 (20).

There is no existing description of $S$. violaceus larvae. Among other of its characters, $S$. violaceus can be distinguished from the other Sperchon larvae described here by its small Dp (length/width > 2,2).

Family: Anisitsiellidae Koenike, 1910

Diagnosis: Dorsal plate bearing 4 or 6 pairs of setae; eye plates on each side fused or separate; coxal plates closely adpressed to one another, with plates I clearly delineated and plates II and III either clearly delineated or fused with suture lines incomplete or nearly obliterated; plates II bearing 1 pair of setae, C3, posterolaterally; plates III bearing 1 or 3 pairs of setae, C4 anteriorly, and in one genus V1 posteromedially and V2 near posterior edges. Excretory pore plate with various shapes bearing 2 pairs of setae (or only their alveoli), $\mathrm{E} 1$ and E2, or 3 pairs of setae including E1 and E2 and $\mathrm{V} 2$ at posterolateral angles; membranous integument surrounding plate bearing 4 pairs of setae, V1 to V4, or 3 pairs with $\mathrm{V} 2$ on excretory pore plate, or 2 pairs with V1 and V2 on coxal plates III. Legs five-segmented, numbers of setae and solenidia on distal leg segments: IL4 7 or 9se+2so, IL5 13-14se+1so; IIL2 6-7se, IIL4 7 or 9 se+2so, IIL5 13-14se+1so; IIIL3 4 se+1so, IIIL4 $8-9$ se+1so, IIIL5 12se. Cheliceral bases medially separated from one another. Palpal claws undivided or bifurcate.

\section{Genus: Bandakia Thor, 1913}

Diagnosis: character states as in family diagnosis, such that: Dorsal plate bearing 4 pairs of setae; eye plates on each side separate; coxal plates with plates I clearly delineated and plates II and III fused with suture lines obliterated except laterally; plates III bearing 1 pair of setae, $\mathrm{C} 4$, anteriorly; excretory pore plate 5 -sided with angles rounded, bearing 2 pairs of setae, E1 and $\mathrm{E} 2$, or 3 pairs with $\mathrm{E} 1$ and $\mathrm{E} 2$ in anterior half and $\mathrm{V} 2$ at posterolateral angles; membranous integument surrounding plate bearing 4 pairs of setae, V1 to V4, or 3 pairs of setae, V1, V3 and V4, with V2 on excretory pore plate; numbers of setae and solenidia on distal leg segments: IL4 9se+2so, IL5 13se+1so; IIL2 7se, IIL4 9 se+2so, IIL5 13se+1so; IIIL4 9se+1so, IIIL5 12se. Palpal claws undivided.

\section{Bandakia concreta Thor, 1913}

Material examined: 4 larvae reared from a clutch sampled from spring no. 300 (NPB), in addition 2 larvae that were attached to hosts from NPB (spring no. 312) and 4 from a spring in Luxemburg (no. LUX QU 23; see Gerecke et al. in press): characters of at most 5 larvae were measured.

Morphology: Habitus of the idiosoma moderately rounded; barely longer than wide (Fig. 11a, b). Length of idiosoma $(n=4)$ 235-238 (236), width 200-205 (203).

Dorsal idiosoma (Fig. 11a): All setae, apart from Lp2, relatively short. Chitin of the dorsal plate showing fine pores. Dp reverse ovate, anteriorly tapering in a rounded tip, length of Dp $(n=3) 220-220$ (220), width 163-175 (168), distance between the two lateral eyes about 45 , distance between median eye capsules 63-65 (64), Mp2-Amdp 25-27 (26), Mp1-Mp1 32-36 (33), Mp2-Mp2 76-80 (78), Lp1-Lp1 15-20 (17), Lp2Lp2 110-120 (115), Mp1-Lp1 8-9 (9), Mp2-Lp2 18-21 (20), Mp1-Mp2 36-42 (38), Lp1-Lp2 45-49 (47), Mp1 8-10 (9), Mp2 17-24 (20), Lp1 12-15 (13), Lp2 57-60 (59), Hu 45-47 (46), Mh3 (n=1) 22, Mh4 36, Lh1 38, Lh2 45, Lh3 32.

Ventral idiosoma (Fig. 11b): Some scars of muscle attachment on the coxal plates. Median separation of the CXI and CXII+III in some specimens asymmetrical. Median length CXI ( $n=3$ ) 84-86 (85), width 44-47 (45), median length CXII+III 80-82 (81), width 94-97 (95), median length CXII (up to the suture) 37-40 (39), median length CXIII 42-43 (42), C1-C2 48-53 (51), C1-Mmcp 27-29 (28), C4-Pmcp 92-96 (94), C1-C4 52-64 (60), C1 18-23 (21), C2 27-34 (31), C3 38-42 (40), C4 19-23 (21), length Expp 30-31 (30), width 4447 (46), E1-E1 13-17 (14), E2-E2 8-8 (8), E1-E2 8-9 (9), E1 and E2 present, but very fine (about $30 \mu \mathrm{m}$ in length; not drawn in Fig. 11b), Exp centrally between the insertions of E1 and E2, V1 anterior, V2 lateroposterior and V3, V4 posterior of Expp, V1 21-23 (22), V2 18-20 (19), V3 23-30 (26), V4 92-105 (98).

Gnathosoma: base 87-88 (88), chelicerae separated, chelicera elongated (Fig. 11c) 73-75 (74), chela (dentate with two small teeth) 13-14 (14), length P2 31-32 (31), width 26-30 (28), length P3 20-22 (21), width 2527 (26), claw 17-18 (18).

Legs $(n=5)$ : Segments of IL and IIL relatively short and robust, segments of IIIL more elongated; suture on I-IIIL2 clearly visible. Empodial claws heavy; lateral claws more slender; both slightly curved.

Leg I (Fig. 11d): total length 213-220 (216), length IL1 (1se) 34-35 (35), IL2 (7se) 46-48 (47), IL3 (4se, 
1so) 33-34 (33), IL4 (9se, 2so) 46-48 (47), IL5 (13se, 1 so) 54-55 (55), height IL1 24-26 (25), IL2 23-25 (24), IL3 22-23 (22), IL4 20-21 (21), IL5 18-19 (19).

Leg II (Fig. 11e): total length 220-227 (223), length IIL1 (1se) 36-36 (36), IIL2 (7se) 45-47 (46), IIL3 (4se, 1so) 34-35 (34), IIL4 (9se, 2so) 48-50 (49), IIL5 (13, 1 so) 57-59 (58), height IIL1 24-26 (25), IIL2 23-25 (24), IIL3 22-23 (23), IIL4 20-21 (20), IIL5 18-20 (19).

Leg III (Fig. 11f): total length 243-256 (250), length IIIL1 (1 se) 48-51 (50), IIIL2 (6se) 42-44 (43), IIIL3 (4se, 1so) 37-40 (39), IIIL4 (9se, 1so) 57-60 (59), IIIL5 (12se) 59-61 (60), height IIIL1 23-25 (24), IIIL2 20-22 (21), IIIL3 18-20 (19), IIIL4 18-18 (18), IIIL5 $15-17$ (16).

No larval description of $B$. concreta has previously been presented; the only described larvae of Bandakia belong to the North American species B. vietsi Cook, 1961, B. borealis Smith, 1979 (both in Smith 1979) and B. phreatica Cook, 1974 (Smith 1982). All these descriptions are accurate and show differences compared with B. concreta. Bandakia vietsi and B. borealis are similar but differ from each other with respect to the smaller dimensions of certain sclerites in $B$. borea lis (see Smith 1979). In contrast to these species and $B$. phreatica, B. concreta is characterized, for example, by the distinct slit-like structure on the posterior Expp. For B. phreatica, a spiny projection of the distal Expp seems to be a specific character (see Smith 1982). The larva of $B$. concreta is easy to distinguish from the other larvae presented here by the characters of the family.

Family: Lebertiidae Thor, 1900

Diagnosis: see Smith (1982) for the diagnosis of the whole family including the North American genus Estelloxus; for the genus Lebertia see below.

\section{Genus: Lebertia Neuman, 1880}

Diagnosis: Dorsal plate bearing 4 pairs of setae; setae Lp2 thick and long; eye plates on each side fused; membranous integument surrounding dorsal plate bearing 8 pairs of long thick setae; coxal plates closely adpressed to one another, with plates I clearly delineated, with suture lines complete and distinct or indistinct medially, and with plates II and III fused, with suture lines obliterated except laterally; plates II bearing 1 pair of setae, C3, posterolaterally; plates III bearing 3 pairs of setae, $\mathrm{C} 4$ anteriorly, $\mathrm{V} 1$ posteromedially and V2 near posterior edges; Excretory pore plate diamond-shaped with rounded apices, broadly convex or attenuated posteriorly, substantially larger than excre- tory pore; bearing 2 pairs of setae, E1 anteriorly and E2 near lateral apices; membranous integument surrounding plate bearing 2 pairs of setae, $\mathrm{V} 3$ and $\mathrm{V} 4$, with V1 and V2 on coxal plates III; numbers of setae solenidia on distal leg segments: IL4 9se+2so, IL5 14se+1so; IIL2 7se, IIL4 9 se+2so, IIL5 14se+1so; IIIL3 4se(+1so), IIIL4 9se+1so, IIIL5 $11 \mathrm{se}$; cheliceral bases slender, medially separated from one another and divergent; palpal claws undivided, with 4 thick proximoventral setae and longer than the palp.

As in the genus Sperchon, the observations concerning leg setation differ: Wainstein (1980) reported the following leg setation for the genus Lebertia: IL1 1se, IL2 $7 \mathrm{se}$, IL3 4se+1so, IL4 9se+2so+1eu, IL5 $13 \mathrm{se}+1 \mathrm{so}+2 \mathrm{eu}$; IIL1 $1 \mathrm{se}$, IIL2 7se; IIL3 4se+1so, IIL4 $9 \mathrm{se}+2 \mathrm{so}+1 \mathrm{eu}$, IIL5 $13 \mathrm{se}+1 \mathrm{so}+2 \mathrm{eu}$; IIIL1 $1 \mathrm{se}$, IIIL2 $6 \mathrm{se}$, IIIL3 4se, IIIL4 9se+1so, IIIL5 $11 \mathrm{se}+1 \mathrm{eu} . \mathrm{Ob}-$ viously, this setation is correct for the eupathidia but differs from Smith (1982) and my own descriptions below with respect to the setation of IIIL3. Wainstein (1980) found larvae without solenidia on this segment; Smith's larvae and the species described below bear an inconspicuous solenidium located distally on IIIL3. There are only a few accurate descriptions of Lebertia larvae of the Palaearctic (e.g. in Ullrich 1976, Wainstein 1980, Martin 2000) and therefore the differential morphology of this genus is little known.

\section{Lebertia cuneifera Walter, 1922}

Material examined: 15 larvae reared from females from spring nos. 300, 312 and 350 (NPB): characters of at most 5 larvae were measured.

Morphology: Habitus of the idiosoma moderately ovate with angular margins anterior and posterior (Fig. $12 \mathrm{a}, \mathrm{b})$. Length of idiosoma 280-296 (289), width 204220 (212).

Dorsal idiosoma (Fig. 12a): Setae $\mathrm{Hu}, \mathrm{Mh}$ and $\mathrm{Lh}$ borne on small chitinous platelets. Dorsal plate with distinct alveolar pattern, Dp reverse ovate, slightly tapering posteriorly. Length of Dp 268-284 (274), width 152-168 (160), Mp2-Amdp 51-56 (53), Mp1-Mp1 3436 (35), Mp2-Mp2 36-41 (38), Lp1-Lp1 16-18 (17), Lp2-Lp2 63-67 (65), Mp1-Lp1 10-13 (11), Mp2-Lp2 33-36 (35), Lp1-Mp2 46-53 (50), Mp1-Lp2 16-20 (18), Mp1 68-72 (70), Mp2 19-21 (20), Lp1 19-21 (20), Lp2 148-155 (152), Hu 115-130 (121), Mh1 128143 (137), Mh2 115-130 (121), Mh3 108-120 (114), Mh4 80-88 (84), Lh1 98-108 (103), Lh2 100-105 (103), Lh3 85-95 (90).

Ventral idiosoma (Fig. 12b): All ventral setae smooth, except for the inconspicuously pinnated setae V1V3; chitin of the coxal plates alveolar. Length CXI 95- 

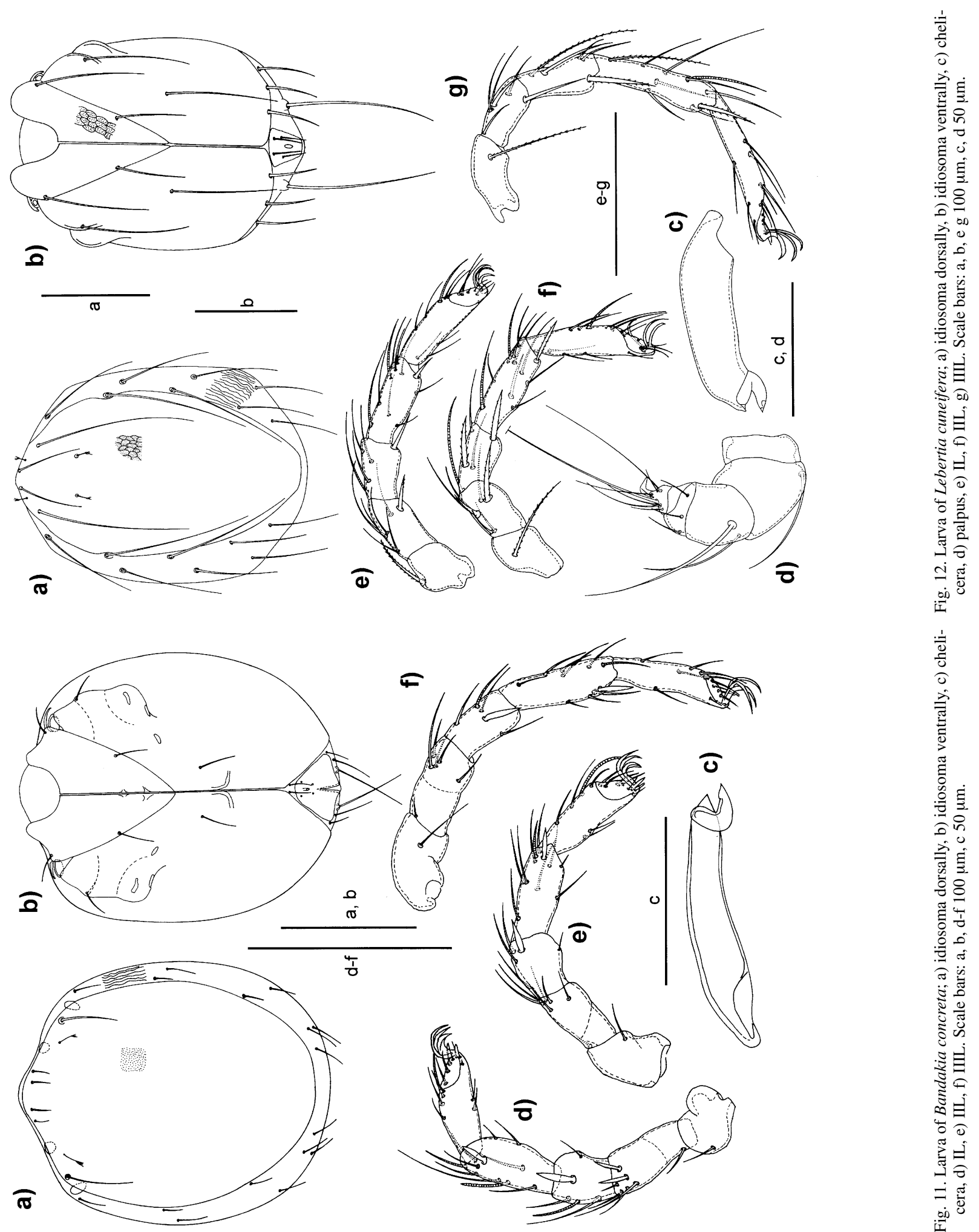

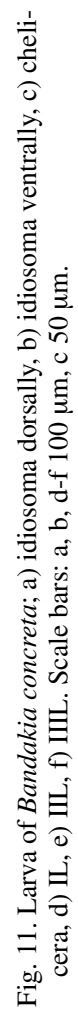


103 (99), width 54-57 (56), length CXII+III 113-115 (114), width 41-43 (42), C1-C2 77-87 (81), C1-Mmcp 19-22 (21), C4-Pmcp 102-107 (106), C1-C4 50-61 (53), C1 67-73 (69), C2 99-105 (101), C3 85-108 (98), C4 103-106 (104), Expp trapezoid but rounded posteriorly; Expp slightly elongated and with setae E2 slightly posteriorly in some specimens, Exp near the posterior margin of the Expp, length Expp 23-31 (28), width 33-37 (35), E1-E1 15-19 (17), E2-E2 22-25 (24), E1 33-38 (35), E2 36-37 (37), V1 51-54 (52), V2 57-63 (60), V3 76-80 (78), V4 158-165 (161).

Gnathosoma: base 75-79 (78), chelicera (Fig. 12c) 76-81 (78), chela stout and dislocated posteriorly, chela 15-16 (15), length P2 (Fig. 12d) 35-37 (37), width 26-28 (28), length P3 25-28 (26), width 22-25 (23), claw 10-11 (10)

Legs: Empodial claw short, stout, simple and falciform; lateral claws less heavy and elongated.

Leg I (Fig. 12e): total length 256-266 (261), length IL1 (1se) 40-42 (41), IL2 (7se) 48-51 (49), IL3 (4se. 1so) 4648 (47), IL4 (9se, 2so, 1eu) 56-57 (57), IL5 (13se, 1so, 2eu) 66-68 (67), height IL1 27-29 (28), IL2 23-24 (23), IL3 22-23 (23), IL4 20-22 (21), IL5 16-19 (18).

Leg II (Fig. 12f): total length 277-286 (281), length IIL1 (1se) 42-45 (43), IIL2 (7se) 49-50 (50), IIL3 (4se, 1so) 45-46 (45), IIL4 (9se, 2so, 1eu) 63-64 (64), IIL5 (13se, 1so, 2eu) 78-81 (79), height IIL1 23-25 (24), IIL2 24-25 (24), IIL3 21-23 (22), IIL4 19-21 (20), IIL5 17-18 (17).

Leg III (Fig. 12g): total length 326-335 (331), length IIIL1 (1se) 52-53 (52), IIIL2 (6se) 48-52 (50), IIIL3 (4se, 1so) 54-56 (55), IIIL4 (9se, 1so) 79-80 (80), IIIL5 (11se, 1eu) 93-94 (93), height IIIL1 22-23 (22), IIIL2 21-22 (21), IIIL3 19-22 (20), IIIL4 17-20 (19), IIIL5 14-15 (15).

Until the description above, the larva of L. cuneifera was unknown. It differs from the other Lebertia larvae described here in the short leg segments I-IIIL4 and the relatively short $\mathrm{C} 1(<75 \mu \mathrm{m})$.

Lebertia lativentris Viets, 1922

Material examined: 1 larva reared from a female from spring no. 300 (NPB): characters of 1 larva were measured.

Morphology: Habitus of the idiosoma moderately ovate (Fig. 13a, b). Length of idiosoma 300, width 240.

Dorsal idiosoma (Fig. 13a): All dorsal setae borne on small platelets, those of Mp1 and Mp2 relatively large. Dp with distinct alveolar pattern, Dp oval and with distinct indentations at the margins where setae
Mh1, Mh2 and Mh3 are located, Dp at the posterior end only slightly smaller than at anterior. Length of Dp 178, width 115, Mp2-Amdp 55, Mp1-Mp1 35, Mp2Mp2 35, Lp1-Lp1 13, Lp2-Lp2 75, Mp1-Lp1 12, Mp2Lp2 41, Lp1-Mp2 45, Mp1-Lp2 30, Mp1 18, Mp2 31, Lp1 78, Lp2 155, Hu 78, Mh1 148, Mh2 130, Mh3 99, Mh4 76, Lh1 128, Lh2 115, Lh3 100.

Ventral idiosoma (Fig. 13b): Setae V1-V3 pinnate, all other ventral setae smooth. Expp triangular with a convex anterior margin. Coxal plates with alveolar pattern. Median length CXI 103, width 55, maximum length CXI 163, median length CXII+III 113, width 113, maximum length CXII+III 125, C1-C2 85, C1Mmcp 25, C4-Pmcp 102, C1-C4 70, C1 81, C2 133, C3 118, C4 108, length Expp 30, width 36, E1-E1 11, E2-E2 23, E1 30, E2 23, V1 51, V2 68, V3 86, V4 163.

Gnathosoma: base 85, chelicera 70, chela 16 .

Legs: Empodial claw short, stout, simple and falciform; lateral claws less heavy and elongated.

Leg I (Fig. 13c): total length 281, length IL1 (1se) 42, IL2 (7se) 42, IL3 (4se, 1so) 55, IL4 (9se, 2so, 1eu) 71, IL5 (13se, 1so, 2eu) 71, height IL1 28, IL2 25, IL3 25, IL4 23, IL5 18.

Leg II (Fig. 13d): total length 293, length IIL1 (1se) 46, IIL2 (7se) 41, IIL3 (4se, 1so) 50, IIL4 (9se, 2so, 1eu) 75, IIL5 (13se, 1so, 2eu) 81, height IIL1 29, IIL2 26, IIL3 25, IIL4 21, IIL5 17.

Leg III (Fig. 13e): total length 363, length IIIL1 (1se) 60, IIIL2 (6se) 50, IIIL3 (4se, 1so) 59, IIIL4 (9se, 1so) 96 , IIIL5 (11 se, 1eu) 98, height IIIL1 28, IIIL2 22, IIIL3 22, IIIL4 20, IIIL5 15.

There were no previous descriptions of larval L. lativentris. The larva differs from the other Lebertia larvae with respect to setae E2, which are longer than those of $E 1$, and by having a relative broad $D p$ (length/width $<1,6$ ).

\section{Lebertia sefvei Walter, 1911}

Material examined: 10 larvae reared from females from spring nos. 300, 304 (NPB) and from a collecting site lying between these two springs: characters of 5 larvae were measured.

Morphology: Habitus of the idiosoma moderately ovate (Fig. 14a, b). Length of idiosoma 296-308 (303), width 204-212 (208).

Dorsal idiosoma (Fig. 14a): All dorsal setae borne on small chitinous platelets, platelets of $\mathrm{Hu}$ and $\mathrm{Mh1}$ Mh3 relatively large. Dp ovate and with an alveolar pattern, Dp with slight indentations near the setae Mh1 and Mh2. Length of Dp 268-280 (274), width 164-168 

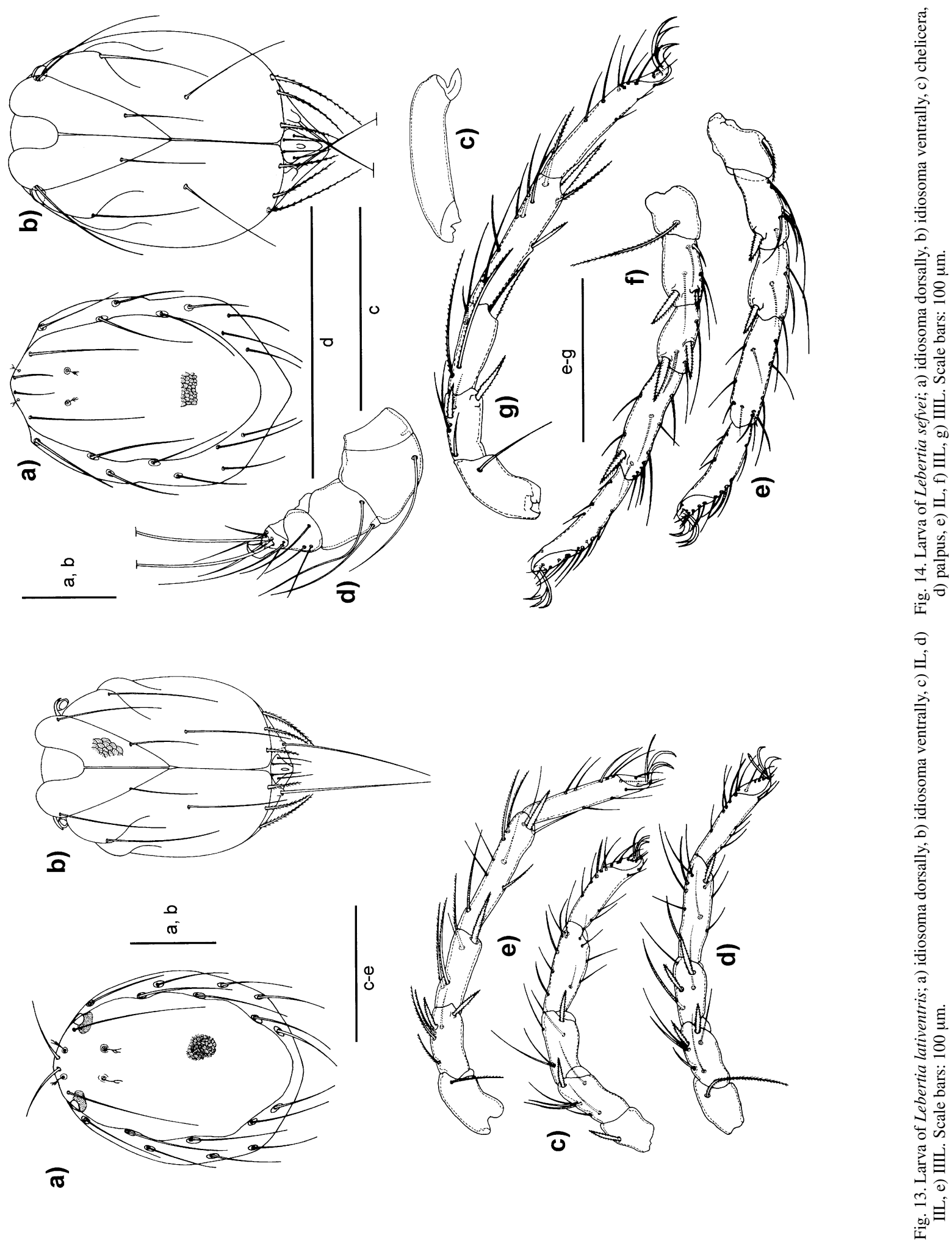
(166), Mp2-Amdp 60-64 (61), Mp1-Mp1 31-34 (33), Mp2-Mp2 32-36 (34), Lp1-Lp1 13-14 (13), Lp2-Lp2 65-68 (67), Mp1-Lp1 11-13 (12), Mp2-Lp2 41-45 (43), Lp1-Mp2 56-59 (57), Mp1-Lp2 18-20 (19), Mp1 48-62 (54), Mp2 22-24 (23), Lp1 18-20 (19), Lp2 125130 (128), Hu 103-111 (107), Mh1 128-133 (130), Mh2 120-130 (125), Mh3 92-98 (95), Mh4 73-81 (77), Lh1 98-103 (100), Lh2 87-92 (90), Lh3 87-89 (88).

Ventral idiosoma (Fig. 14b): Expp kite-shaped with a rounded anterior margin, setae E1 near the anterior margin, setae E2 posterior of the widest extension of the Expp and also placed near the margin of the Expp, Exp positioned centrally, setae V1-V3 pinnate, all other ventral setae smooth. Length CXI 103-110 (106), width 55-60 (59), length CXII+III 105-110 (109), width 85-95 (89), C1-C2 74-80 (78), C1-Mmcp 24-26 (25), C4-Pmcp 105-115 (110), C1-C4 60-67 (64), C1 77-85 (81), C2 102-111 (107), C3 98-106 (102), C4 107-112 (109), length Expp 26-28 (27), width 35-37 (36), E1-E1 12-13 (12), E2-E2 23-24 (23), E1 28-32 (30), E2 30-33 (31), V1 50-52 (51), V2 62-77 (66), V3 72-87 (79), V4 138-160 (154), V1-V2 23-25 (24).

Gnathosoma: base 83-86 (85), chelicera (Fig. 14c) 82-85 (84), chela 12-15 (13), length P2 (Fig. 14d) 3538 (36), width 27-30 (28), length P3 25-28 (27), width 23-24 (24), claw 13-14 (13).

Legs: Empodial claw short, stout, simple and falciform; lateral claws less heavy and elongated.

Leg I (Fig. 14e): total length 280-292 (287), length IL1 (1se) 42-45 (43), IL2 (7se) 50-53 (52), IL3 (4se, 1so) 51-52 (52), IL4 (9se, 2so, 1eu) 69-70 (70), IL5 (13se, 1so, 2eu) 68-72 (70), height IL1 26-34 (29), IL2 23-24 (23), IL3 22-24 (23), IL4 20-21 (20), IL5 17-17 (17).

Leg II (Fig. 14f): total length 292-306 (299), length IIL1 (1se) 42-47 (45), IIL2 (7se) 50-53 (51), IIL3 (4se, 1so) 47-48 (47), IIL4 (9se, 2 so, 1eu) 72-75 (74), IIL5 (13se, 1so, 2eu) 81-83 (82), height IIL1 26-27 (27), IIL2 23-24 (24), IIL3 22-24 (23), IIL4 19-21 (20), IIL5 16-17 (16).

Leg III (Fig. 14g): total length 343-361 (353), length IIIL1 (1se) 48-52 (51), IIIL2 (6se) 52-53 (52), IIIL3 (5se) 56-61 (60), IIIL4 (9se, 1 so) 92-94 (93), IIIL5 (11se, 1eu) 95-101 (98), height IIIL1 23-25 (24), IIIL2 21-23 (22), IIIL3 20-23 (21), IIIL4 18-20 (19), IIIL5 14-16 (15).

No descriptions of the larva of $L$. sefvei were previously available. Although the larva bears a striking resemblance to $L$. lativentris, it differs with respect to the similar lengths of E1 and E2 and the relative smallness of the Dp (length/width $>1,6$ ).

\section{Lebertia zschokkei Koenike, 1902}

Material examined: 2 larvae reared from females from spring no. 360 (NPB): characters of 1 larva were measured.

Morphology: Habitus of the idiosoma moderately ovate (Fig. 15a). Length of idiosoma 288, width 208.

Dorsal idiosoma: Length of Dp 255, width 143.

Ventral idiosoma (Fig. 15a): Setae C4, V1-V3, E1 and E2 pinnate, setae C1-C3 and V4 simple. Expp compressed kite-shaped; anteriorlateral margins of the plate indistinct. Setae E1 delimited from the anterior margin of Expp, setae E2 only just anterior of the Exp and also far distant from the Expp margin, Exp near the posterior margin of Expp. Median length CXI 93, width 55, maximum length CXI 153, median length CXII+III 90, width 90, maximum length CXII+III 105, C1-C2 80, C1-Mmcp 20, C4-Pmcp 102, C1-C4 50, C1 91, C2 130, C3 128, C4 110, length Expp 29, width 36, E1-E1 15, E2-E2 20, E1 29, E2 33, V1 47, V2 58, V3 65, V4 158.

Gnathosoma: chelicera (Fig. 15b) 81, chela 13, length P2 37, width 27, length P3 27, width 24, claw 14.

Legs: Empodial claw simple and falciform; lateral claws more elongated.

Leg I (Fig. 15c): total length 256, length IL1 (1se) 34, IL2 (7se) 51, IL3 (4se, 1so) 45, IL4 (9se, 2so, 1eu) 52, IL5 (13se, 1so, 2eu) 74, height IL1 28, IL2 26, IL3 23, IL4 21, IL5 19.

Leg II (Fig. 15d): total length 283, length IIL1 (1se) 40, IIL2 (7se) 50, IIL3 (4se, 1so) 49, IIL4 (9se, 2so, 1eu) 62, IIL5 (13se, 1so, 2eu) 82, height IIL1 27, IIL2 27, IIL3 23, IIL4 23, IIL5 20.

Leg III (Fig. 15e): total length 317, length IIIL1 (1se) 49, IIIL2 (6se) 50, IIIL3 (4se, 1 so) 53, IIIL4 (9se, 1so) 72, IIIL5 (11se, 1eu) 93, height IIIL1 28, IIIL2 24, IIIL3 22, IIIL4 23, IIIL5 19.

Walter (1922a) had previously described the larva of L. zschokkei, obviously on the basis of an engorged specimen after parasitization. Since few measurements are given in Walter's description, an accurate comparison is not possible but his drawings show an Expp with an Exp located at the posterior margin of the plate. The distal position of the Expp, together with the short median length of CXII-III $(<100 \mu \mathrm{m})$, make it possible to distinguish L. zschokkei from the other lebertiid larvae described here.

Family: Hygrobatidae Koch, 1842

Diagnosis: Dorsal plate large, covering almost the entire idiosoma in length and bearing 4 pairs of setae; 
anterior eyes borne on small eye plates and posterior eyes on membranous integument; coxal plates I-III on each side fused with each other and bearing 4 pairs of coxal setae; excretory pore plate very large, much wider than long; E1 and E2 either absent and represented by setal pores or minute setae; V1 present at posterior end of coxal plates I-III or on the excretory pore plate; V2 on excretory pore plate; V4 very long, whip like and borne on large elongated projections; bases of chelicerae fused with each other; chela dentate; palpal segment 4 and 5 very short, P5 thumb-like, palpal claw simple; legs I to III five-segmented and each with three claws.

In the past the setae E1 and E2 were reported as absent in the genera Hygrobates and Atractides (Prasad $\&$ Cook 1972). New observations revealed that these setae sometimes are present but they are often very small. Wainstein (1980) reported leg chaetotaxy for the Hygrobatidae: IL1 1se, IL2 7se, IL3 4se+1so+1eu, IL4 9se+2so+1eu, IL5 9-12se+1so+1-2eu; IIL1 1se, IIL2 $7 \mathrm{se}$, IIL3 4se+1so+0-1eu, IIL4 9-11se+2so+01eu, IIL5 9-12se+1so+1-2eu; IIIL1 1se, IIIL2 6se, IIIL3 4se+0-1so, IIIL4 9-12se+1so, IIIL5 810 se+0so+1-2eu. For the subfamily Hygrobatinae Koch, 1942, Wainstein (1980) found the following chaetotaxy: IL $11 \mathrm{se}$, IL2 $7 \mathrm{se}$, IL3 $4 \mathrm{se}+1 \mathrm{so}+1 \mathrm{eu}$, IL4 $9 \mathrm{se}+2 \mathrm{so}+1 \mathrm{eu}$, IL5 $12 \mathrm{se}+1 \mathrm{so}+1-2 \mathrm{eu}$; IIL1 1se, IIL2 $7 \mathrm{se}$, IIL3 $4 \mathrm{se}+1 \mathrm{so}+1 \mathrm{eu}$, IIL4 9se $+2 \mathrm{so}+1 \mathrm{eu}$, IIL5 $12 \mathrm{se}+1 \mathrm{so}+1-2 \mathrm{eu}$; IIIL1 $1 \mathrm{se}$, IIIL2 $6 \mathrm{se}$, IIIL3 $4 \mathrm{se}+1 \mathrm{so}$, IIIL4 9se+1so, IIIL5 10se+0so+1-2eu.

Genus: Hygrobates Koch, 1837

Diagnosis: Setae V1 located on posterior end of coxal plates I-III; on the gnathosomal base, setae Hy2 longer than Hy1; P1 not fused with P2; chela with two teeth.

\section{Hygrobates norvegicus (Thor, 1897)}

Material examined: 41 larvae reared from females from spring nos. 300, 308, 312 (NPB): if not otherwise indicated, measurements refer to 5 larvae.

Morphology: Habitus of the idiosoma moderately elongated (Fig. 16a, b), larva only a little more narrowed anteriorly than posteriorly. Length of idiosoma $(n=41)$ 280-356 (323), width 184-236 (214).

Dorsal idiosoma (Fig. 16a): Dp large and alveolar, length of Dp 268-348 (314), width 156-236 (188), Mp2-Amdp (n=5) 44-51 (46), Mp1-Mp1 76-78 (77), Mp2-Mp2 71-73 (72), Lp1-Lp1 54-60 (57), Lp2-Lp2 113-130 (117), Mp1-Lp1 16-19 (18), Mp2-Lp2 22-23 (22), Lp1-Mp2 38-42 (40), Mp1-Lp2 20-25 (22), Mp1 85-98 (92), Mp2 15-17 (16), Lp1 17-18 (18), Lp2 98110 (102), Hu 118-125 (122), Mh1 128-133 (129),
Mh2 120-130 (123), Mh3 63-68 (66), Mh4 45-55 (49), Lh1 75-88 (80), Lh2 68-73 (71), Lh3 70-80 (76).

Ventral idiosoma (Fig. 16b): In most specimens, Expp distinctly incised posteriorly; E1 and E2 very short and pin-like. Median length CXI-III (from the median gnathosomal bay to the posterior end of CXIIII) $(n=36)$ 185-238 (212), width CXI-III $(n=5)$ 95-110 (104), common median length of both CXI-III 193225 (202), C1-C2 30-48 (39), C1-Mmcp 21-24 (23), C4-Pmcp 130-165 (148), C1-C4 77-89 (83), C1 62-67 (64), C2 45-49 (47), C3 72-79 (74), C4 93-110 (100); on Expp, lateral of setae E1, distinct undulated or serrated chitinous patterns; length Expp 52-65 (59), width 108-123 (116), E1-E1 14-19 (17), E2-E2 27-31 (29), E1 1-3 (2), E2 2-3 (3), setae V1 often approaching the anterior margin of Expp, V1 48-57 (52), V2 lying far distally on Expp and near the anteriorlateral angle of Expp, V2 43-53 (48), V3 58-62 (60), V4 198-225 (211), V1-V1 30-46 (40), V2-V2 85-100 (91), V3-V3 96-101 (99), V4-V4 70-82 (75), V1-V2 32-37 (35), length of projecting base of V4 35-41 (38).

Gnathosoma: base 74-88 (84), chelicera (Fig. 16c) 77-82 (80), chela 17-20 (18), length P2 34-36 (35), width 30-31 (30), length P3 18-20 (20), width 23-25 (24), claw 16-18 (17).

Legs: Leg I (Fig. 16d, e): total length 219-241 (229), length IL1 (1se) 31-35 (33), IL2 (7se) 43-47 (44), IL3 (4se, 1so, 1eu) 39-44 (41), IL4 (9se, 2so, 1eu) 48-53 (51), IL5 (12se, 1so, 2eu) 58-62 (60), height IL1 22-24 (23), IL2 20-21 (20), IL3 19-20 (20), IL4 20-21 (21), IL5 19-21 (20).

Leg II (Fig. 16f, g): total length 241-265 (252), length IIL1 (1se) 32-35 (33), IIL2 (7se) 44-48 (46), IIL3 (4se, 1so, 1eu) 42-47 (44), IIL4 (9se, 2so, 1eu) 58-63 (60), IIL5 (12se, 1so, 2eu) 65-72 (69), height IIL1 2232 (24), IIL2 19-21 (20), IIL3 19-21 (20), IIL4 18-20 (20), IIL5 17-19 (18).

Leg III (Fig. 16h, i): total length 267-311 (289), length IIIL1 (1se) 33-39 (37), IIIL2 (6se) 45-50 (48), IIIL3 (4se, 1so) 48-59 (53), IIIL4 (9se, 1so) 64-79 (70), IIIL5 (10se, 1eu) 77-84 (82), height IIIL1 20-22 (21), IIIL2 19-21 (20), IIIL3 19-20 (20), IIIL4 19-21 (20), IIIL5 16-18 (17).

Some fragmentary descriptions of the larva of $H$. norvegicus were previously given (Walter 1922a, Viets 1923a, b, Ullrich 1976). Apart from the main character of the genus, viz. the location of the setae V1, no taxonomically important characters were described in the studies of Walter and Viets. Ullrich (1976) illustrated the larva in detail and emphasized the height of the larva and the distal notch of the Expp, a notch that was 


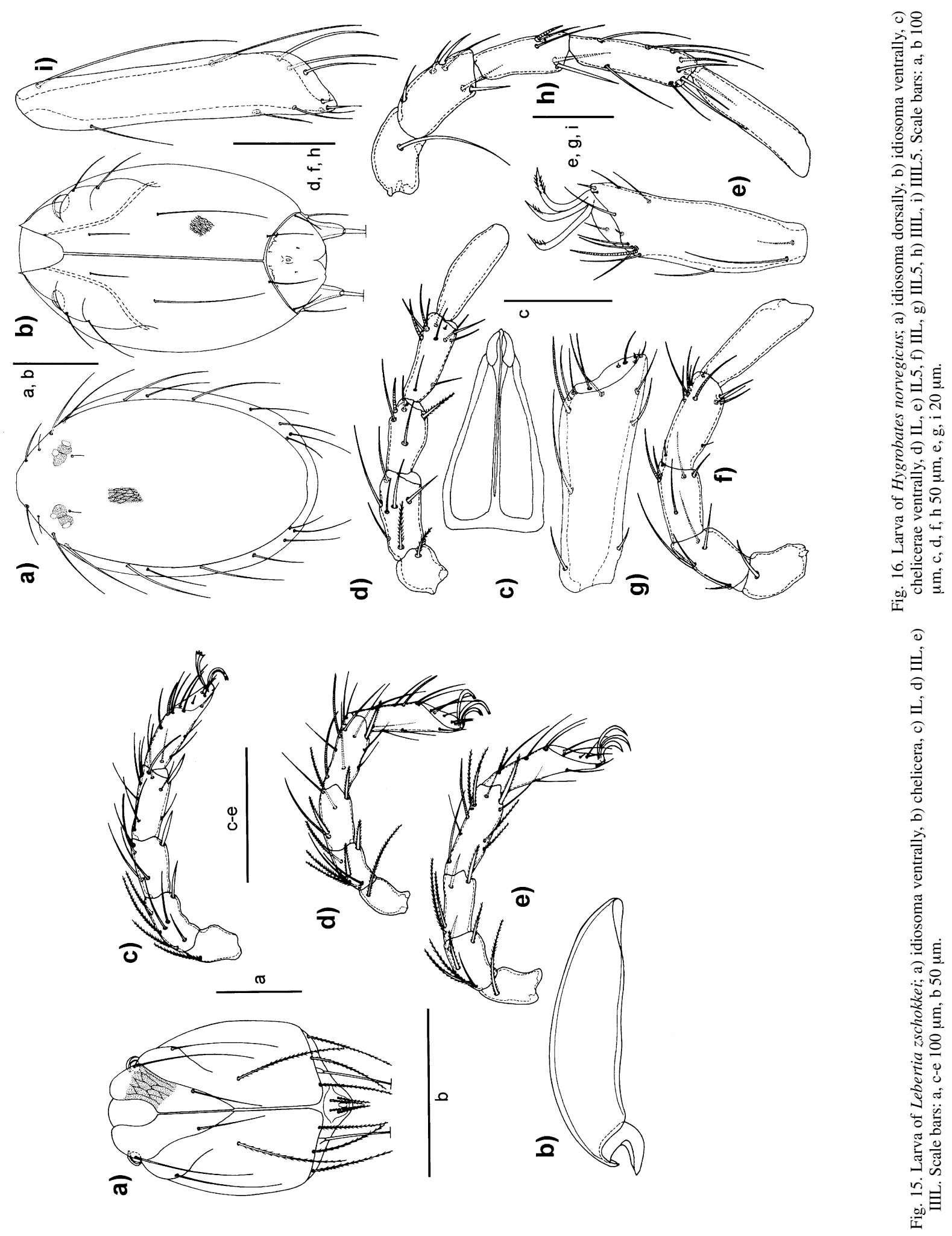


absent from the other Hygrobates larvae that he described (H. calliger Piersig, 1896, H. fluviatilis Ström, 1768). Other Hygrobates larvae (e.g. H. nigromaculatus Lebert, 1879; Martin \& Davids 2002 or others; see Wainstein 1980) certainly show a indentation in the distal margin of the Expp but never such a distinct notch as that of $H$. norvegicus. Only $H$. longiporus Thor, 1898 , has an excretory pore plate that is similar to that of $H$. norvegicus (Wainstein 1980).

In some specimens of Atractides larvae, the location of the setae V1 on the excretory pore plate or on the coxal plates is not readily seen. For this species, the caudal indentation of the excretory pore plate and the greater length of several characters (e.g. the length of C4-Pmpc) are good characters for separating the larva of $H$. norvegicus from the larvae of the Atractides species described here.

\section{Genus Atractides Koch, 1837}

Diagnosis: Setae V1 located on the excretory pore plate; on the gnathosomal base, setae Hy2 shorter than Hy1; P1 fused with P2; chela with one teeth.

All the larvae of Atractides described in the following have relatively small legs on which the chaetotaxy is difficult to observe. The numbers of setae in the descriptions refer to clearly seen setae and the eupathidia were omitted completely. Whether the lack of some setae in some species reflects a reduction in chaetotaxy remains open.

\section{Atractides adnatus Lundblad, 1956}

Material examined: 10 larvae reared from females from spring nos. 360 and 390 (NPB): characters of 5 larvae were measured.

Morphology (Fig. 17): Habitus of the idiosoma moderately long (Fig. 17a, b). Length of idiosoma 225230 (227), width 133-145 (140).

Dorsal idiosoma (Fig. 17a): Dp relatively narrow and slightly tapered posteriorly, largest width in the posterior third of the plate, length 220-225 (222), width 103-108 (106), Mp2-Amdp 31-33 (32), Mp1-Mp1 41-50 (45), Mp2-Mp2 39-43 (40), Lp1-Lp1 33-38 (35), Lp2-Lp2 70-74 (72), Mp1-Lp1 9-12 (10), Mp2Lp2 15-18 (17), Lp1-Mp2 24-27 (25), Mp1-Lp2 18-22 (20), Mp1 20-21 (21), Mp2 17-19 (18), Lp1 38-42 (40), Lp2 78-93 (84), Hu 48-54 (51), Mh1 92-98 (95), Mh2 88-102 (93), Mh3 32-43 (39), Mh 4 32-42 (35), Lh1 41-45 (43), Lh2 27-31 (28), Lh3 28-32 (29).

Ventral idiosoma (Fig. 17b): Expp relatively high. Length CXI-III (from the median gnathosomal bay to the posterior end of CXI-III) 168-175 (172), width CXI-
III 70-83 (77), common median length of both CXI-III 145-153 (149), maximum length of CXI-III 208-215 (211), interior diameter of the urstigma 9-11 (10), C1C2 42-45 (43), C1-Mmcp 13-14 (13), C4-Pmcp 82-88 (85), C1-C4 55-60 (56), C4-median margin of CXI-III 26-28 (27), C1 28-31 (29), C2 35-38 (37), C3 37-43 (41), C4 68-78 (74), length Expp 29-36 (33), width 5358 (56), E1-E1 10-17 (13), E2-E2 15-18 (17), E1-E2 911 (10), E1 and E2 small and fine setae, V1 26-30 (29), V2 28-33 (30), V3 31-38 (35), V4 145-170 (158), V1V1 21-24 (22), V2-V2 40-46 (43), V3-V3 47-53 (51), V4-V4 35-38 (37), V1-V2 15-17 (16), length of projecting base of V4 9-10 (10), width 7-8 (7).

Gnathosoma: base 68-77 (72), chelicera (Fig. 17c, d) 62-65 (63), chela 14-17 (14), length P1+2 (Fig. 17e) 32-34 (33), width 23-27 (24), length P3 18-21 (20), width 16-20 (19), claw 10-13 (12), long seta on P3 84-89 (86).

Legs: Leg I (Fig. 17f, g): total length 167-179 (173), length IL1 (1se) 26-30 (27), IL2 (7se) 32-34 (33), IL3 (7se) 32-33 (33), IL4 (4se, 1so, 1eu) 35-37 (36), IL5 (12se, 1so, 2eu) 42-45 (43), height IL1 16-18 (17), IL2 17-18 (17), IL3 16-17 (17), IL4 17-18 (18), IL5 14-16 (15).

Leg II (Fig. 17h): total length 176-189 (182), length IIL1 (1se) 27-31 (29), IIL2 (7se) 32-35 (33), IIL3 (4se, 1 so) 31-32 (31), IIL4 (9se, 1 so) 37-38 (38), IIL5 (12se, 1so) 49-53 (51), height IIL1 17-19 (18), IIL2 16-18 (17), IIL3 17-18 (17), IIL4 17-18 (18), IIL5 $15-18$ (17).

Leg III (Fig. 17i): total length 215-229 (223), length IIIL1 (1se) 35-39 (38), IIIL2 (6se) 35-37 (36), IIIL3 (4se, 1so) 38-40 (39), IIIL4 (8se, 1so) 46-50 (49), IIIL5 (10se) 61-63 (62), height IIIL1 14-16 (15), IIIL2 15-17 (16), IIIL3 15-16 (16), IIIL4 16-17 (17), IIIL5 13-14 (14).

To date, the larva of $A$. adnatus was undescribed. It differs from the other Atractides larvae of the present study in its small Expp and Dp and with respect to various morphometric characters mainly on the Expp.

Atractides macrolaminatus Láska, 1956

Material examined: 6 larvae reared from females from spring no. 397 (NPB): characters of at most 5 larvae were measured.

Morphology: Larva relatively small and habitus of the idiosoma distinctly elongated and parallel to the lateral margins of the body (Fig. 18a, b). Length of idiosoma $(n=5)$ 205-220 (213), width 110-133 (125).

Dorsal idiosoma (Fig. 18a): Dp longish, anteriorly stout and posteriorly slightly tapering and rounded, 


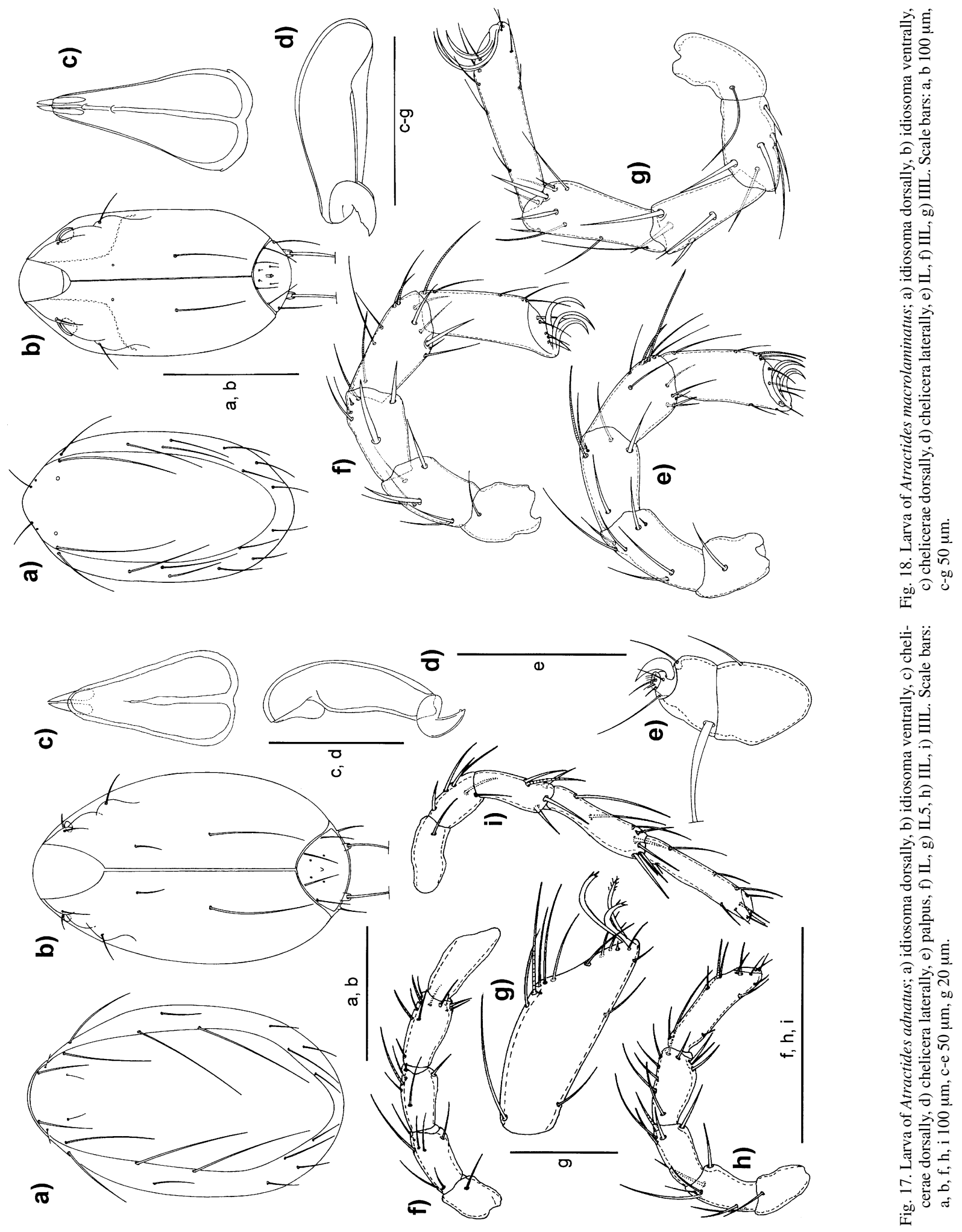


length of $\mathrm{Dp}(\mathrm{n}=4)$ 193-205 (199), width 52-59 (56), Mp2-Amdp (n=1) 23, Mp1-Mp1 45, Mp2-Mp2 41, Lp1-Lp1 35, Lp2-Lp2 84, Mp1-Lp1 9, Mp2-Lp2 24, Lp1-Mp2 18, Mp1-Lp2 28, Mp2 15, Lp1 20, Hu 48, Mh1 79, Mh2 46, Mh3 38, Mh4 34, Lh1 38, Lh2 26, Lh3 27.

Ventral idiosoma (Fig. 18b): Setae E1 and E2 fine but clearly visible. Length CXI-III ( $\mathrm{n}=5$ ) (from the median gnathosomal bay to the posterior end of CXI-III) 153-163 (157), width CXI-III 52-59 (56), common median length of both CXI-III 135-148 (141), maximum length of CXI-III 190-203 (197), interior diameter of the urstigma 12-13 (13), gnathosomal bay $(n=3)$ 30-38 (35), C1-C2 ( $\mathrm{n}=4$ ) 42-47 (43), C1-Mmcp 11-15 (13), C4-Pmcp 70-73 (72), C1-C4 49-56 (54), C4-median margin of CXI-III ( $\mathrm{n}=5)$ 22-23 (23), $\mathrm{C} 1(\mathrm{n}=1) 22$, $\mathrm{C} 2(\mathrm{n}=3)$ 26-32 (30), C3 (n=4) 35-38 (37), C4 $(n=5)$ 52-58 (55), Expp slit-like in shape and placed almost directly between the alveoli of E2, length Expp 27-32 (30), width 47-52 (50), E1-E1 8-9 (8), E2-E2 14-16 (15), E1-E2 7-10 (9), V1 15-24 (21), setae V2 slightly offset from the angle of the Expp, V2 22-28 (25), V3 32-38 (35), V4 (n=3) 158-170 (163), V1-V1 (n=2) 2020 (20), V2-V2 44-45 (45), V3-V3 (n=5) 46-51 (48), V4-V4 30-33 (32), V1-V2 15-16 (15), length of projecting base of V4 6-7 (7).

Gnathosoma: base $(\mathrm{n}=4)$ 58-66 (63), chelicera (Fig. $18 \mathrm{c}$, d) $(\mathrm{n}=5)$ 57-63 (61), chela 15-17 (16), length $\mathrm{P} 1+2(\mathrm{n}=4)$ 26-30 (28), width 22-25 (24), length P3 12-16 (15), width 17-21 (19), claw ( $\mathrm{n}=5)$ 11-12 (12), long seta on P3 (n=2) 88-92 (90).

Legs $(\mathrm{n}=5)$ : Leg I (Fig. 18e): total length 151-173 (164), length IL1 (1se) 25-28 (26), IL2 (7se) 33-36 (34), IL3 (4se, 1so, 1eu) 28-33 (31), IL4 (9se, 2so) 2935 (33), IL5 (10se, 1so) 36-41 (39), height IL1 15-18 (17), IL2 16-17 (16), IL3 16-17 (17), IL4 17-18 (18), IL5 15-19 (17).

Leg II (Fig. 18f): total length 156-182 (172), length IIL1 (1se) 22-30 (27), IIL2 (7se) 30-34 (32), IIL3 (4se, 1so, 1eu) 28-31 (30), IIL4 (9se, 2so) 34-38 (36), IIL5 (9se, 1so) 42-49 (47), height IIL1 14-18 (16), IIL2 1718 (17), IIL3 16-18 (17), IIL4 15-18 (17), IIL5 17-18 (17).

Leg III (Fig. 18g): total length 184-213 (201), length IIIL1 (1se) 25-33 (31), IIIL2 (6se) 33-37 (34), IIIL3 (4se) 34-37 (36), IIIL4 (9se) 43-46 (44), IIIL5 (9se) 49-60 (57), height IIIL1 15-16 (16), IIIL2 15-17 (16), IIIL3 15-16 (16), IIIL4 15-17 (17), IIIL5 14-16 (15).

No previous larval descriptions of A. macrolaminatus are available. The larva of A. macrolaminatus can be distinguish from the other Atractides larvae descri- bed here by its small habitus, which is correlated with a small Dp, and by the short distance between seta $\mathrm{C} 4$ and Pmcp.

\section{Atractides panniculatus (Viets, 1925)}

Material examined: 8 larvae reared from females from spring no. 300 (NPB): characters of 5 larvae were measured.

Morphology: Larva relatively large and habitus of the idiosoma moderately long (Fig. 19a, b). Length of idiosoma 268-280 (274), width 176-192 (184).

Dorsal idiosoma (Fig. 19a): Dp anteriorly rounded, posteriorly tapering to a blunt, rather than pointed, margin, length of Dp 260-280 (269), width 144-156 (150), Mp2-Amdp 32-35 (34), Mp1-Mp1 (n=3) 56-62 (58), Mp2-Mp2 (n=4) 43-46 (44), Lp1-Lp1 (n=3) 4547 (46), Lp2-Lp2 (n=4) 82-85 (48), Mp1-Lp1 10-10 (10), Mp2-Lp2 18-21 (20), Lp1-Mp2 (n=3) 26-26 (26), Mp1-Lp2 17-19 (18), Mp1 (n=2) 15-19 (17), Mp2 $(\mathrm{n}=3)$ 21-21 (21), Lp1 (n=4) 48-51 (49), Lp2 (n=5) 8798 (92), Hu 48-53 (51), Mh1 99-107 (104), Mh2 100108 (105), Mh3 54-60 (56), Mh4 45-48 (47), Lh1 4248 (44), Lh2 36-39 (38), Lh3 35-38 (37).

Ventral idiosoma (Fig. 19b): Common median length of both CXI-III 185-188 (186), width CXI-III 83-90 (88), maximum length of CXI-III 248-258 (252), interior diameter of the urstigma 14-16 (15), C1-C2 56-61 (59), C1-Mmcp 16-19 (17), C4-Pmcp 99-103 (101), C1-C4 63-68 (65), C4-median margin of CXI-III 2728 (28), C1 19-25 (22), C2 35-43 (39), C3 46-57 (52), C4 (relatively heavy setae) 87-97 (94), Expp about twice as wide as long, length Expp 43-47 (45), width 91-94 (93), Exp rounded, alveoli of setae E1+E2 inconsiderable, E1-E1 17-19 (18), E2-E2 23-25 (24), E1 and E2 small longish pegs, V1 17-19 (18), setae V2 near the outermost edge of Expp, V2 26-27 (26), V3 39-43 (41), V4 175-190 (179), V1-V1 28-31 (30), V2V2 78-86 (82), V3-V3 85-95 (89), V4-V4 65-72 (70), V1-V2 30-33 (32), length of projecting base of V4 1719 (18).

Gnathosoma: base 80-89 (84), chelicera (Fig. 19d, e) 66-70 (68), chela 16-19 (17), length P1+2 (Fig. 19c) 30-32 (31), width 26-30 (28), length P3 17-21 (20), width 20-23 (22), claw 12-13 (13), long seta on P3 3538 (37).

Legs: Leg I (Fig. 19f, g): total length 203-216 (211), length IL1 (1se) 32-35 (34), IL2 (6se) 37-41 (39), IL3 (4se, 1so, 1eu) 37-40 (39), IL4 (9se, 2so, 1eu) 45-47 (46), IL5 (11se, 1so, 1eu) 52-53 (52), height IL1 18-20 (19), IL2 17-18 (17), IL3 17-18 (17), IL4 16-19 (18), IL5 15-17 (16). 
Leg II (Fig. 19h): total length 208-226 (218), length IIL1 (1se) 30-35 (33), IIL2 (6se) 41-43 (42), IIL3 (4se, 1so) 37-39 (38), IIL4 (9se, 2so) 46-50 (48), IIL5 (11se, 1so) 54-59 (57), height IIL1 19-21 (20), IIL2 16-18 (17), IIL3 15-17 (16), IIL4 17-19 (18), IIL5 16-17 (16).

Leg III (Fig. 19i): total length 252-273 (264), length IIIL1 (1se) 37-42 (40), IIIL2 (6se) 42-46 (44), IIIL3 (4se, 1so) 42-47 (45), IIIL4 (9se, 1so) 60-63 (61), IIIL5 (10se, 2eu) 71-75 (73), height IIIL1 16-18 (17), IIIL2 17-18 (17), IIIL3 17-18 (17), IIIL4 17-18 (17), IIIL5 14-15 (14).

No previous description of the larva of A. panniculatus is available. It differs from all Atractides larvae described here with respect to its length; thus, the Dp and Expp are longer or wider, respectively, than in the other Atractides larvae.

\section{Atractides walteri (Viets, 1925)}

Material examined: 10 larvae reared from females from spring nos. 308, 350 and 360 (NPB): characters of 5 larvae were measured.

Morphology: Habitus of the idiosoma moderately ovate (Fig. 20 a, b). Length of idiosoma 230-238 (233), width 160-170 (166).

Dorsal idiosoma (Fig. 20a): Dp appearing stout, anteriorly rounded, posteriorly tapering and ending rounded, length of Dp 205-225 (217), width 133-150 (139), Mp2-Amdp 27-30 (29), Mp1-Mp1 43-54 (50), Mp2Mp2 33-45 (41), Lp1-Lp1 32-40 (37), Lp2-Lp2 $72-89$ (83), Mp1-Lp1 9-11 (10), Mp2-Lp2 21-23 (22), Lp1Mp2 21-22 (21), Mp1-Lp2 18-23 (21), Mp1 43-52 (47), Mp2 24-27 (26), Lp1 18-24 (20), Lp2 58-69 (66), $\mathrm{Hu}$ 77-89 (82), Mh1 73-79 (75), Mh2 68-75 (71), Mh3 27-35 (32), Mh4 27-31 (29), Lh1 35-44 (41), Lh2 2734 (31), Lh3 25-29 (28).

Ventral idiosoma (Fig. 20b): Length CXI-III (from the median gnathosomal bay to the posterior end of CXI-III) 180-185 (183), width CXI-III 75-82 (79), common median length of both CXI-III 150-158 (154), maximum length of CXI-III 208-218 (213), C1C2 45-48 (46), C1-Mmcp 13-14 (14), C4-Pmcp 88-90 (89), C1-C4 55-59 (57), C4-median margin of CXI-III 28-31 (30), C1 26-28 (27), C2 29-37 (33), C3 43-52 (47), C4 65-70 (68), Exp slit-like in shape and central to setae E1 and E2, Expp distinctly longer than wide, length Expp 41-42 (42), width 62-66 (64), E1-E1 1114 (12), E2-E2 20-21 (20), E1 and E2 small and very fine; internal area of Expp (between seta E1 and E2) in most individuals appearing to extend into the plate; V1 24-33 (29), V2 28-31 (30), V3 offset from the lateral angle of Expp, V3 41-47 (44), V4 163-170 (167), V1V1 22-25 (24), V2-V2 51-55 (53), V3-V3 60-65 (63), V4-V4 42-46 (44), V1-V2 20-22 (21), length of projecting base of V4 8-10 (9).

Gnathosoma: base 66-72 (69), chelicera (Fig. 20c) 57-60 (59), chela 15-16 (15), length P1+2 27-31 (29), length P3 14-17 (16), claw 9-11 (10), long seta on P3 90-93 (92).

Legs: Leg I (Fig. 20d): total length 170-184 (178), length IL1 (1se) 26-29 (28), IL2 (7se) 32-36 (34), IL3 (4se, 1so, 1eu) 31-33 (32), IL4 (9se, 2so, 1eu) 37-39 (38), IL5 (10se, 1so, 2eu) 44-47 (46), height IL1 17-18 (18), IL2 16-17 (17), IL3 16-18 (17), IL4 17-18 (17), IL5 15-16 (16).

Leg II (Fig. 20e, f): total length 183-199 (193), length IIL1 (1se) 29-30 (30), IIL2 (6se) 34-36 (35), IIL3 (4se, 1so) 30-34 (32), IIL4 (9se, 1so) 40-44 (42), IIL5 (10se) 50-55 (53), height IIL1 17-18 (17), IIL2 16-18 (17), IIL3 16-17 (16), IIL4 16-17 (17), IIL5 15-17 (16).

Leg III (Fig. 20g, h): total length 211-232 (222), length IIIL1 (1se) 30-35 (32), IIIL2 (6se) 36-38 (37), IIIL3 (4se) 36-40 (39), IIIL4 (9se) 48-53 (51), IIIL5 (10se) 61-66 (64), height IIIL1 16-17 (16), IIIL2 15-17 (16), IIIL3 15-16 (15), IIIL4 16-18 (17), IIIL5 14-15 (14).

The larva of A. walteri is described in the present study for the first time. It resembles A. adnatus most closely but differs in the width of Expp and with respect to the distances V2-V2 or E1-E2.

\section{Discussion}

\section{Taxonomical remarks}

In spite of the progress in the field of larval taxonomy, this branch of taxonomy is still widely neglected. The variability of the characters and the practicality of using key characters in determining unknown larvae are therefore not well understood, which are my reasons for pointing out some observations that have been made in the present study and to which more attention should be paid in future studies:

In my own slides of the various specimens of distinct species, some larval structures were of markedly variable quality. Certain features obviously show variation in shape (e.g., Expp in Lebertia larvae) or length (e.g., many setae); this may be an expression of the variability within individuals in one population or between populations. However, as in all taxonomic studies, this also implies that it is highly desirable to be 


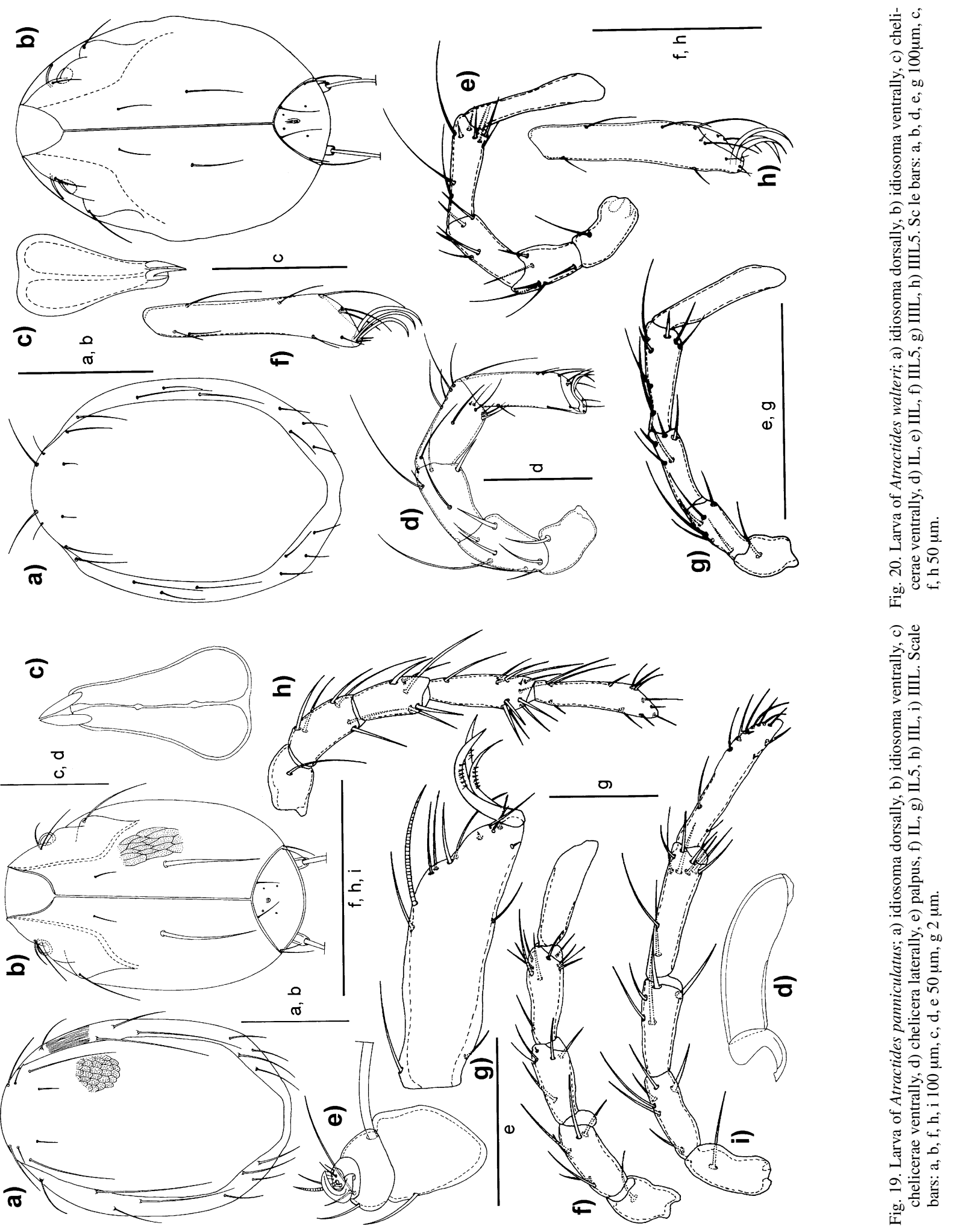


able to examine more than one individual when undertaking larval descriptions. Some characters of larval morphology are self-evidently difficult to observe because of their small size (e.g. leg chaetotaxy in small taxa) or because chitinous structures are not clearly delimited from the integument (e.g. excretory pore, dorsal plates). Thus, the characters given within a description must be carefully checked in as many individuals as possible to prevent the misidentification or misinterpretation of such characters.

Another "alarming" fact has become apparent, especially in Hygrobates norvegicus (see description above), with respect to observations made on freshly hatched and living larvae by using a binocular eyepiece. Even larvae derived from an identical clutch vary distinctly in size. In $H$. norvegicus, this results, for example, in a large variation in length or width of the dorsal plate. In the case of descendants of the same clutch, this phenomenon is probably caused by the unequal distribution of reserve substances in single eggs or the development of the larvae being different depending on the position of the egg within the clutch. The descendants of the various clutches possibly differ because of the nutritional status of their mothers. Thus, relative characters (such as the ratios of length/width, relative length of setae, etc.) seem to be more appropriate for separating species than, for example, simple lengths.

Sometimes, the supposedly definitive differences in larval morphology between related species change depending on whether freshly hatched larvae or engorged larvae derived from infested hosts are examined. This can be explained by marginal growth within the parasitic stage. This point should be checked in larval descriptions and may also be an explanation for the marked variability in larval morphology.

\section{Loss of parasitism?}

In the past, single cases of the loss of parasitism have been observed, i.e. the larvae do not hatch or show further development to the nymphal stage after a short free-living period without feeding. For some particular habitats (streams, interstitial, springs), a loss of parasitism has been supposed (Walter 1917, Mitchell 1957, Schwoerbel 1959, Besch 1969). This has been substantiated by the assumed problems that larvae experience in reaching their host, i.e. hydraulic stress or current for stream-living water mites or difficulties in the synchronization of host and parasite life cycles in the case of spring-living mites. The phenomenon of the loss of larval parasitism has however been reviewed and no restriction with respect to a limited habitat has been found (B.P. Smith 1998). The few comprehensive studies concerning larval parasitization of whole water mite communities in selected streams have shown that nearly all species have a parasitic larval stage (Efford 1963, Ullrich 1976, Martin 2000) and underline Smith's conclusion that the loss of parasitism is an exception in the life cycle of water mites and probably, in most cases, reduces the species' fitness. The loss of parasitism obviously brings a loss in genetic heterozygosity for the respective species (Bohonak 1999).

The present study shows that at least larval development and the hatching of larvae of most spring-living species occur. The analysis of insect emergence in Alpine springs additionally reveals hosts for most of the species of the present study (Martin, unpublished data).

State of larval descriptions in general and the situation for spring-living species

Prasad (1991) stresses the relative ignorance of larval taxonomy in water mites by revealing the small amount of progress achieved between the publication of his overview and the first true beginning of larval taxonomy by Prasad \& Cook (1972). He also argues that there has been a general decline in taxonomy, a situation that still shows no signs of improvement. In North America, the work of I. M. Smith and a few others has culminated in a key to water mite genera (Smith et al. 2001) but, in the Palaearctis, no such important advance has been made apart from the Russian paper of Wainstein (1980).

Only about $20 \%$ of the more than 1000 species and subspecies of the West-Palaearctis (see Viets 1978) have received any kind of attention regarding larval description (own unpublished data); this value includes all fragmentary descriptions and the purely verbal descriptions that are given with no illustrations and those that are of no taxonomical benefit.

Based on the present study, a compilation of the key characters for the described species has been possible that enables the determination of larvae for most of the water mite species found in the National Park of Berchtesgaden (Martin, unpublished data).

About 120 crenophilous and crenobiontic species have been found in the springs of the West-Palaearctis (see Viets 1978). If one also considers verbal descriptions without illustrations and/or with inadequate figures of no taxonomical benefit, data on the larval morphology of only approximately $20 \%$ of spring-living water mites were available before the present study (own unpublished data). Thus, the larval morpholo- 
gy of spring-dwelling water mites is known at the similar low level as that for all water mites in the WestPalaearctis. Against this background, the present study has substantially improved our knowledge of this subject.

\section{Outlook and perspectives}

Larval taxonomy is a necessary tool for elucidating parasite-host associations in water mites. Since many studies have shown a strong relationship of water mites to their lotic habitats (see Di Sabatino et al. 2000), it seems worthwhile to establish the habitat relationships of their hosts and to clarify the host specificity of the water mites parasitizing their respective hosts. The life cycle of most spring- and stream-dwelling water mites could possibly depend on their crenoor rheobiontic hosts.

The best way to extend larval taxonomy and to answer such questions in the future will be to examine the larvae of all the species of water mites at selected collecting sites. Such work has been carried out for some streams (Ullrich 1976, Martin 2000) but never for springs as in the present study. The knowledge of the species inventory of a specific habitat should enable us to compile a key for all the larvae of the respective species. Finally, parasitic larvae can then be determined and the host spectrum of each species can be examined.

In order for the more frequent consideration of parasitic water mite larvae in taxonomical and also in ecological and/or parasitological studies, a preliminary key for the larvae should be compiled. In contrast to the existing key for the North American genera (Smith et al. 2001), a key for the West-Palaearctis should include all hitherto presented larval descriptions with comments as to their usability in taxonomy. Such a key should also bring together the characters that are species-specific and that would better reveal the extent of open fields in larval taxonomy than could the occurrence of simple oversights (e.g. Smith \& Oliver 1986). Moreover, the unclear aspects in larval morphology mentioned above should be investigated and any results obtained should be entered into the key. An appropriate appreciation of the paper of Wainstein (1980) is also necessary. This key together with a review of all larval descriptions of West-Palaearctic species should also enable a more detailed comparison of some species or species groups for which the taxonomic status in North America is still unclear.

\section{Acknowledgements}

The present study was part of a project supported by a grant of the foundation 'Pro Acarologia Basiliensis' (Basel, Switzerland).
I wish to thank Reinhard Gerecke (Tübingen, Germany) for providing me with many slides and also undissected water mite larvae from the National Park of Berchtesgaden and from elsewhere in Europe. I also express my appreciation to Helmut Franz from the administration of the National Park (Berchtesgaden, Germany) for his support of the study and for assistance in all aspects of the field work. Last but not least, the author would also like to thank Ms. Sabine Geisler (University of Kiel, Germany) for inking the figures.

\section{References}

Bader C. 1974. — Die Sperchoniden der glandulosus-Gruppe. Arch. Hydrobiol., 73, 470-491.

Besch W. 1969. - South American Arachnida. Pages 723-740 in Fittkau E. J., Illies, J., Klinge H., Schwabe G. H. \& Sioli H. (Eds) Biogeography and Ecology in South America, vol 2. Dr. W. Junk Publishers, The Hague.

Biesiadka E. \& Cichocka E. 1984. - Studies on the morphology of larvalstages of Water mites (Hydracarina). 1. Description of three species of the genera Protzia Piersig and Sperchon, Kramer. Ann. Zool., 38, 159-171.

Böttger K. 1977. - The general life cycle of fresh water mites (Hydrachnellae, Acari). Acarologia, 18, 496-502.

Bohonak A.J. 1999. - Effect of insect-mediated dispersal on the genetic structure of postglacial water mite populations. Heredity, $82,451-461$.

Di Sabatino A., Gerecke R. \& Martin P. (2000). — The biology and ecology of lotic water mites (Hydrachnidia). Freshwater Biol., 44, 47-62.

Efford I.E. 1963. - The parasitic ecology of some watermites. $J$. Anim. Ecol., 32, 141-156.

Gerecke R. 1996. - Untersuchungen über Wassermilben der Familie Hydryphantidae (Acari, Actinedida) in der Westpalaearktis, II. Die Wassermilben der Familie Hydryphantidae Piersig, 1896 in den Mittelmeerländern. Arch. Hydrobiol./Suppl., 77, 337-513.

Gerecke R. \& Di Sabatino A. 1996. - Water mites (Acari, Hydrachnellae) and spring typology in Sicily. Crunoecia, 5, 35-41.

Gerecke R. \& Tuzovskij P. 2001. - The water mite Rutripalpus limicola Sokolow, 1934: new data on morphology and biology, and considerations on the systematic position of the monotypic family Rutripalpidae (Acari, Hydrachnidia). J. Nat. Hist., 35, 931-944.

Gerecke R., Franz H. \& Schrankel I. 2002. — Forschung im Nationalpark Berchtesgaden von 1978 bis 2001. Nationalpark Berchtesgaden, Forschungsbericht, 46, 67-72.

Gerecke R., Meisch C., Stoch F., Acri F. \& Franz H. 1998. - Eucrenon-hypocrenon ecotone and spring typology in the alps of Berchtesgaden (Upper Bavaria, Germany). A study of microcrustacea (Crustacea: Copepoda, Ostracoda) and water mites (Acari: Halacaridae, Hydrachnellae). Pages 167-182 in Botosaneanu L. (Ed.) Studies in crenobiology. Backhuys, Leiden.

Gerecke R., Stoch, F., Meisch, C. \& Schrankel I. in press. - Die Fauna der Quellen und des hyporheischen Interstitials in Luxemburg unter besonderer Berücksichtigung der Acari, Ostracoda und Copepoda. FERRANTIA - Trav. Sci. MNHN.

Hubault E. 1927. — Contribution à l'étude des invertébrés torrenticoles. Bull. biolog. France \& Belg., Paris. Suppl. 9, 388 pp.

Imamura T. 1950. — On the life-history of Partnunia uchidai, a water mite parasitic on stone-flies. Annotnes zool. Jap., 24, 54-58.

Jones R K.H. 1967. — Descriptions of the larvae of Aturus scaber Kramer, Protzia eximia Protz and Piona uncata Koenike with notes on the life-histories of the later two. [Hydracarina]. Ann. Limnol., 3, 231-247. 
Krendowskij M.E. 1878. — Über die Erscheinung der Metamorphose bei den Wassermilben. Trudy Obscestva Ispytatelej Prirody pri Imperatorskom Charkovskom Universi, 12, 221-286.

Lundblad O. 1924. - Ein unerwartetes, interessantes Verhältnis in der Epimorphose einer schwedischen Hexalebertia. Ent. Tidskr. 45, 72-79.

Lundblad O. 1927. — Die Hydracarinen Schwedens. I. Beitrag zur Systematik, Embryologie, Ökologie und Verbreitungsgeschichte der schwedischen Arten. Zool. Bidr., 11, 185-540.

Lundblad O. 1962. — Die Hydracarinen Schwedens II. Ark. Zool., $14,1-635$.

Martin P. 1998. — Zur Autökologie der Wassermilben (Hydrachnidia, Acari) zweier norddeutscher Tieflandbäche. Ph.D. Thesis, Univ. Kiel : 269 pp.

Martin P. 2000. - Larval morphology and host-parasite associations of some stream living water mites (Hydrachnidia, Acari). Arch. Hydrobiol./Suppl., 121/3-4, Monogr. Stud., 269-320.

Martin P. \& Davids C. 2002. — Life history strategies of Hygrobates nigromaculatus, a widespread palaearctic water mite (Acari, Hydrachnidia, Hygrobatidae). Pages 101-110 in: Bernini F., Nannelli, G., Nuzzaci, G. \& de Lillo, E. (Eds) Acarid Phylogeny and Evolution. Adaptations in mites and ticks. Kluwer Academic Publishers, Dortrecht, The Netherlands.

Mitchell R. 1957. - Major evolutionary lines in water mites. Syst. Zool., 6, 137-148.

Motas C. 1928. - Contribution à la connaissance des Hydracariens français particulièrement du Sud-Est de la France. Trav. Labor Hydrobiol. Pisc. Univ. Grenoble, 20, 373 pp.

Motas C. 1929. - Sur le développement postembryonnaire de $\mathrm{Ca}$ lonyx brevipalpis (Maglio) et sur les affinités des Protziidae. Ann. scientif. Univ. Jassy, 16, 250-262.

Münchberg P. 1954. - Kurze Mitteilung über die an Steinfliegen (Plecoptera) schmarotzenden Wassermilben-Larven. Arch. Hydrobiol., 49 (3), 414-420.

Piersig G.R. 1896-99. — Deutschlands Hydrachniden. Zoologica, 19 (22), $601 \mathrm{pp}$

Prasad V. 1991. - The taxonomy of water mite larvae in last two decades (Acarina: Hydracarina). Pages 459-464 in Dusbábek F. \& Bukva V. (Eds) Modern Acarology. vol. 1. Academia, Prague and SPB Academic publishing bv, The Hague.

Prasad V. \& Cook D.R. 1972. - The taxonomy of water mite larvae. Mem. Amer. Ent. Inst., 18, 326 pp.

Schwoerbel J. 1959. - Ökologische und tiergeographische Untersuchungen über die Milben (Acari, Hydrachnellae) der Quellen und Bäche des südlichen Schwarzwaldes und seiner Randgebiete. Arch. Hydrobiol., 24, 385-546.

Smith B.P. 1998. - Loss of larval parasitism in parasitengonine mites. Exp. Appl. Acarol., 22, 187-200.

Smith I.M. 1976. — A study of the systematics of the water mite family Pionidae (Prostigmata: Parasitengona). Memoirs of the Entomological Society of Canada, 98, $24 \mathrm{pp}$.

Smith I. M. 1979. - A review of water mites of the family Anisitsiellidae (Prostigmata: Lebertioidea) from North America. Can. Ent., 111, 529-550.

Smith I.M. 1982. - Larvae of water mites of the genera of the superfamily Lebertioidea (Prostigmata: Parasitengona) in North America with comments on phylogeny and higher classification of the superfamily. Can. Ent., 114, 901-990.
Smith I.M. 1991. — Water mites (Acari: Parasitengona: Hydrachnidia) of spring habitats in Canada. In: Williams, D. D. \& Danks H. V. (Eds) Arthropods of springs, with particular reference to Canada. Mem. ent. Soc. Can., 155, 141-167.

Smith I.M. \& Oliver D.R. 1986. - Review of parasitic associations of larval water mites (Acari: Parasitengona: Hydrachnidia) with insect hosts. Can. Ent., 118, 407-472.

Smith I.M., Cook D.R. \& Smith B. P. 2001. — Water mites (Hydrachnida) and other arachnids. Pages 551-659 in: Thorp J. H. \& Covich J. H. (Eds). Ecology and Classification of North American Freshwater Invertebrates. Academic Press, San Diego.

Soar C.D. 1901. - Note on the occurrence of larval water-mites on various aquatic animals. J. Quekett microsc. $\mathrm{Cl}$. (s. 2), 8, 65-66.

Sparing I. 1959. — Die Larven der Hydrachnellae, ihre parasitische Entwicklung und ihre Systematik. Parasitol. Schriftenreihe, 10, 1-165.

Tuzovskij P.V. 1981. - Postembryonic stages of Torrenticola amplexa (Koenike, 1908) (Acariformes, Torrenticolidae). Entomol. Obozrenie, 60, 205-212.

Tuzovskij P.V. 2000. - A new species of the water mite genus Thyas Koch from Magadan Province of Russia (Acariformes: Hydryphantidae). Zoosyst. Rossica, 8, 243-250.

Ullrich F. 1976. - Biologisch-ökologische Studien an rheophilen Wassermilben (Hydrachnellae, Acari), unter besonderer Berücksichtigung von Sperchon setiger (Thor 1898). Ph. D. Thesis, Univ. Kiel, $241 \mathrm{pp}$

Viets K. 1923a. - Hydracarinen aus Quellen. Arch. Hydrobiol./Suppl., 3, 205-596.

Viets K. 1923b. - Hydracarina. Wassermilben. In: Schulze P. (Ed.) Biologie der Tiere Deutschlands, Teil 21. Bornträger, Berlin, 29-52.

Viets K. 1925. — Beiträge zur Kenntnis der Hydracarinen aus Quellen Mitteleuropas. Zool. Jb., Abt. Syst., 50, 451-596.

Viets K. 1928. - Zur Mikrofauna einer Quelle auf der Insel Herdla bei Bergen (Norwegen). Bergens Mus. Arb., 5, 16 pp.

Viets K. 1936. - Wassermilben oder Hydracarina (Hydrachnellae und Halacaridae). In: Dahl F. (Ed.) Die Tierwelt Deutschlands und der angrenzenden Meeresteile nach ihren Merkmalen und ihrer Lebensweise. Gustav Fischer, Jena, 575 pp.

Viets K.O. 1978. - Hydracarina. In: Illies J. (Ed.) Limnofauna Europaea, Gustav Fischer, Stuttgart, 154-181.

Wainstein B.A. 1980. — Opredelitel lichinok vodjanych kleshchei. Inst. Biol. Vnutrenn. Vod., Nauka, 238 pp.

Walter C. 1915. - Notizen über die Entwicklung torrentikoler Hydracarinen. Zool. Anz. 45, 442-456.

Walter C. 1917. - Beitrag zur Kenntnis der Entwicklung bachbewohnender Milben. Verh. naturf. Ges. Basel, 28, 148-164.

Walter C. 1922a. - Hydracarinen aus den Alpen. Rev. Suisse Zool., 29 (7), 227-411.

Walter C. 1922b. — Die Hydracarinen der Alpengewässer. Denkschr. schweizer. naturf. Ges., 58 (2), 60-251. 